\title{
Equations of State of Iron Sulfide and Constraints on the Sulfur Content of the Earth
}

\author{
Thomas J. Ahrens
}

\author{
Seismological Laboratory, California Institute of Technology, Pasadena, California 9//25
}

\begin{abstract}
New shock and release wave data for pyrrhotite $\left(\mathrm{Fe}_{0} \mathrm{~S}\right)$ obtained over the pressure range of 3-158 GPa (0.03-1.58 Mbar) suggest that this mineral undergoes a major shock-induced phase change(s) with an onset in the range 2.7-3.8 GPa. Free-surface velocities of $\mathrm{Fe}_{0} \mathrm{~S}$ released from states between 8.9 and 24.7 $\mathrm{GPa}$ indicate a maximum postshock density of $\sim 5.54 \mathrm{~g} / \mathrm{cm}^{3}$. A pressure of $\sim 25 \mathrm{GPa}$ appears to be required to drive the phase transition(s) to completion. A density for the high-pressure phase (hpp) consistent with present static high-pressure $X$ ray data, $\sim 5.34 \mathrm{~g} / \mathrm{cm}^{3}$, was used to calculate a zeropressure, adiabatic bulk modulus of $126-128 \mathrm{GPa}$ for the hpp. Release adiabat measurements centered at 152 and $158 \mathrm{GPa}$ are consistent with the assumption that the Hugoniot curve in the 25- to 158-GPa range reflects the properties of a denser polymorph, possibly with eight-fold coordination, which may be similar to the local bonding of sulfur in the liquid core of the earth. Similar, but less well constrained, reductions are presented for pyrite, $\mathrm{FeS}_{2}$, based on the three data points of Simakov et al. (1974) in the pressure range 88-320 GPa. These are inferred to represent the behavior of an unknown hpp (approximate zero-pressure density of $5.3 \mathrm{~g} / \mathrm{cm}^{3}$ ) and indicate that this phase forms at a pressure above $\sim 29 \mathrm{GPa}$. Reduction of these data yields a zero-pressure bulk modulus for the hpp in the range 205-244 GPa. The raw Hugoniot data for $\mathrm{Fe}_{0.8} \mathrm{~S}, \mathrm{FeS}_{2}$, and $\mathrm{Fe}$ when constrained to the seismologically obtained density-pressure profiles of the outer core of the earth indicate a systematic decrease of apparent sulfur content from 10 to $6.5 \%$ with depth. When the shock data are reduced to isotherms, a nearly constant sulfur content in the range 9-12\% is inferred. Using these bounds on the sulfur content of the core, and depending on whether an olivine or pyroxene mantle stoichiometry is assumed, the earth can be modeled as being depleted in $\mathbf{S}$ by a factor ranging from 1.7 to 3.2 with respect to the abundances of $\mathrm{Si}$ and from 2.8 to 7.5 relative to the abundance of $\mathrm{Fe}$, in $\mathrm{CCl}$ carbonaceous chondrites. It is concluded that although the shock wave data permit the major light element in the core to be sulfur, the earth can be modeled as being depleted in sulfur, along with other volatile elements. A systematic relation, $C_{0}(\mathrm{~km} / \mathrm{s})=7.15-0.47 \bar{V}$, was also discovered upon comparison of the inferred densities and bulk sound speeds $\left(C_{0}\right)$ of the hpp's of the iron sulfides with other measurements for 12 sulfides and elemental sulfur. Here $\bar{V}$ is the volume (in cubic centimeters) per mole of atoms.
\end{abstract}

\section{INTRODUCTION AND BACKGROUND}

Birch [1952] first pointed out the possibility that a lighter element such as $\mathbf{S i}$, or $\mathbf{C}$ in the Earth's core, may account for its apparently lower density and higher seismic parameter than that of pure iron. Knopoff and MacDonald [1960] compared the shock compression data to $400 \mathrm{GPa}(4 \mathrm{M}$ bar) for pure iron [Al'tshuler et al., 1958a] and other elements with the seismologically determined pressure-density and pressure-seismic velocity relations for the earth's core and concluded that the mean atomic number $m$ of the core was about 23 , which is significantly less than that for iron $(m=26)$. Birch [1964] and McQueen and Marsh [1966] concluded, on the basis of new shock data for iron and iron-nickel, that the core was less dense than pure iron or iron-nickel by 8 and $10 \mathrm{wt} \%$, respectively. The nature of the light element(s) which may be present in the earth's core has been critically reviewed by Jacobs [1975], Ringwood [1975, 1977], and Brett [1976].

The concept that sulfur is present in the interiors of the terrestrial planets in significant quantities has been revived, after an early suggestion of Goldschmidt [1922], by Mason [1966], Murthy and Hall [1970, 1972], Hall and Murthy [1971], Lewis [1971], Anderson [1972] Usselman [1975b], Murthy [1976], and Smith [1977] on the basis of elemental abundances in enstatite chondrites and in a large class of iron and stony meteorites, and from the theoretical considerations of mineral condensation sequences, [e.g., Grossman, 1972; Lewis, 1972]. A major point emphasized by Murthy and Hall [1970, 1972], Murthy [1976], and Ringwood [1975, 1977] is that the crust and

Copyright @ 1979 by the American Geophysical Union. mantle are depleted in S relative to $\mathrm{CC} 1$ carbonaceous chondrites.

Brett and Bell [1969], Ryzhenko and Kennedy [1973], and Usselman [1975a] have shown that the Fe-FeS eutectic composition is relatively insensitive to pressure. The effect of the polymorphism of FeS [Taylor and Mao, 1970], Ni content, and pressure, and via a very considerable extrapolation (based, in part, on earlier shock data [King and Ahrens, 1973]), was used to infer that the eutectic composition remains in the 15-17 wt $\% \mathrm{~S}$ range at core pressures [Usselman, 1975b]. This result implies a sulfur content of the earth closer to solar and chondritic abundances than is obtained in the present paper.

Credible density versus depth models for Mars have been constructed which satisfy the presently limited data with a core varying from $\mathrm{Fe}-\mathrm{FeS}$ eutectic composition to pyrrhotite $\mathrm{Fe}_{0.8} \mathrm{~S}$ stoichiometries [Anderson, 1972; Johnston and Toksöz, 1977; Okal and Anderson. 1978].

Finally, the hypothesis that sulfur is the major light element in the core, because of the low melting point of the Fe-FeS eutectic $\left(\sim 1150^{\circ} \mathrm{C}\right.$ at $10 \mathrm{GPa}$ [Usselman, 1975a]), allows a relatively low temperature regime for the evolution of the mantle upon formation and gravitational settling of the core. Shaw [1978] demonstrated that the core will, for plausible accretional histories, accumulate $\sim 50 \%$ more gravitational (thermal) energy than the mantle which, for a case containing iron sulfide, does not require the total melting of the silicates in the mantle. Thus the retention of some volatiles such as $\mathrm{H}_{2} \mathrm{O}$ and $\mathrm{CO}_{2}$ in the mantle and crust relative to solar abundances and the lack of depletion of the heavy noble gases [Fanale and Cannon, 1971] and possibly the heavier halogens such as iodine [Buolos and Manual, 1971] can be understood. 
In the present paper, constraints on the possible content of sulfur in the outer and inner core of the earth are calculated on the basis of new shock compression data extending to $\sim 160$ $\mathrm{GPa}$ (1.6 Mbar) for $\mathrm{Fe}_{0.8} \mathrm{~S}$ (pyrrhotite) and existing data for iron [Al'tshuler et al., 1962; McQueen et al., 1970]. These results, which supplement earlier data reported by King and Ahrens [1973] and several new data for $\mathrm{FeS}_{2}$ extending to 320 GPa (3.2 Mbar) reported by Simakov et al. [1974], are analyzed and reduced to isothermal equations of state. These reduced data are in turn used to obtain apparent sulfur contents via comparison with pressure-density data for the core obtained from inversion of the earth's free oscillation spectra [e.g., Hart et al., 1977; Gilbert and Dziewonski, 1975].

In the case of FeS, troilite, reconnaissance studies of its polymorphism under high pressure with diamond anvil $\mathrm{X}$ ray apparati are reported by Taylor and Mao [1970] and more recently by Pichulo et al. [1976]. The latter authors report two phase changes: the first, a minor transition of the initial distorted NiAs structure, involves a density increase of $\sim 1 \%$ in the 3.3- to 3.7-GPa range, and a second, occurring between 5.7 and $7.4 \mathrm{GPa}$, has an apparent density increase of $\sim 15 \%$. This latter phase, FeS(III), was tentatively indexed as an orthorhombic structure.

Previous equation of state studies for pyrite, $\mathrm{FeS}_{2}$, include the early static compression study of Bridgman [1949] to 3 $\mathrm{GPa}$, a series of ultrasonic measurements on single crystals summarized by Simmons and Wang [1971], static X ray compression data to $27 \mathrm{GPa}$ reported by Clendenen and Drickamer [1966], and, most recently, some shock compression data to $320 \mathrm{GPa}$ [Simakov et al., 1974]. The latter data, which demonstrate polymorphism in $\mathrm{FeS}_{2}$ above $\sim 30 \mathrm{GPa}$, are analyzed in parallel with the new data for pyrrhotite to place constraints on the possible sulfur content of the core.

\section{Experimental Procedures for Shock Experiments on Pyrrhotite Single Crystals}

A series of shock experiments with final shock stresses in the range 2.6-158 GPa were carried out on randomly oriented aliquots cut from three single crystals of natural pyrrhotite (Tables 1 and 2). Following Walsh and Christian [1955], it is assumed that the mean principal stresses are essentially equal to the shock stress, and both are considered equivalent to pressure in the following treatment. Sixteen samples of irregular outline were selected to be crack and inclusion free on the

TABLE 1. Microprobe Analyses of Pyrrhotite Specimens

\begin{tabular}{lccc}
\hline Element & Crystal $\mathrm{A}^{*}$ & Crystal B $\dagger$ & Crystal C $¥$ \\
\hline $\mathrm{Fe}$ & 61.40 & 61.46 & 58.92 \\
$\mathrm{~S}$ & 39.01 & 39.90 & 39.41 \\
$\mathrm{Ni}$ & 0.03 & 0.02 & 0.29 \\
$\mathrm{Ti}$ & 0.01 & 0.001 & $\ldots$ \\
$\mathrm{Ca}$ & 0.01 & 0.0002 & $\ldots$ \\
$\mathrm{Mg}$ & 0.01 & 0.003 & $\ldots$ \\
$\mathrm{Total}$ & 100.47 & 101.38 & 98.62 \\
Equivalent & $\mathrm{Fe}_{0.809} \mathrm{~S}$ & $\mathrm{Fe}_{0.884} \mathrm{~S}$ & $\mathrm{Fe}_{0.858} \mathrm{Ni}_{0.004} \mathrm{~S}$ \\
$\quad$ & & & \\
\hline
\end{tabular}

Analyses by A. Chodos, California Institute of Technology. "Santa Eulalia, Mexico (United States National Museum \#7570); shots $260,258,240,241,242$, and 245.

†Crucero Mine, Columbia (Ward's Natural Science Establishment), average of five analyses; shots $360,376,385,381,364,363,361$, and 360 .

¥Same source as Crystal B, average of two analyses; shots LGG 12 and LGG 19.
TABLE 2. X Ray Diffraction Data for Pyrrhotite (Crystal C)

\begin{tabular}{ccccc}
\hline $\begin{array}{c}\text { Lattice } \\
\begin{array}{c}\text { Spacing, } \\
(\tilde{\mathrm{A}})\end{array}\end{array}$ & $\begin{array}{c}\text { Relative } \\
\text { Intensity } \\
\left(I / I_{0}\right)^{a}\end{array}$ & $\begin{array}{c}\text { Miller } \\
\text { Index } \\
(h k l)\end{array}$ & $\begin{array}{c}\text { Lattice } \\
\text { Spacing, } \\
(\tilde{A})\end{array}$ & $\begin{array}{c}\text { Relative } \\
\text { Intensity } \\
\left(I / I_{0}\right)^{b}\end{array}$ \\
\hline 5.74 & 4 & $111,11 \overline{1}$ & 5.75 & 2 \\
5.26 & 2 & $20 \overline{2}, 202$ & 5.27 & 0.05 \\
4.68 & 2 & $113,11 \overline{3}$ & 4.68 & 1 \\
2.98 & 5 & 400,220 & 2.966 & 9 \\
$2.64^{c}$ & 9 & $22 \overline{4}$ & 2.635 & 9 \\
$c$ & & 224,404 & 2.621 & 8 \\
$2.063^{d}$ & 10 & $22 \overline{8}$ & 2.057 & 10 \\
$2.050^{d}$ & 10 & 228 & 2.047 & 9 \\
1.721 & 9 & 620,040 & 1.714 & 8 \\
1.438 & 2 & 804,444 & 1.434 & 2 \\
1.424 & 2 & 0.0 .16 & 1.421 & 3 \\
1.103 & 6 & $e$ & $f$ & \\
0.999 & 4 & $e$ & $f$ & \\
\hline
\end{tabular}

${ }^{a}$ Obtained with $\mathrm{Co}, \mathrm{K}_{\alpha}$ radiation; analyst, S. Hill (California Institute of Technology).

${ }^{b}$ Corbett [1974].

${ }^{C}$ Broad reflection may combine reflection of lattice spacing from 2.621 and $2.64 \hat{A}$.

${ }^{d}$ Split lines.

${ }^{e}$ Not indexed.

'Not reported.

basis of visual observation and observation with commercially obtained radiographs. After surface grinding to a thickness tolerance of $\pm 0.005 \mathrm{~mm}$, density was determined by weighing in air and in temperature monitored reagent grade toluene using the temperature corrections of Berman [1939]. As indicated in Table 3, the uncertainty in an individual bulk density determination was $\pm 0.003 \mathrm{~g} / \mathrm{cm}^{3}$, whereas the average density of all samples is $4.6025 \pm 0.0174$ (std. dev.) $\mathrm{g} / \mathrm{cm}^{3}$. This average density is slightly lower than the (appropriate) value $\rho_{0 x}=4.609 \mathrm{~g} / \mathrm{cm}^{3}$ calculated from a linear fit

$$
\rho_{0 x}\left(\mathrm{~g} / \mathrm{cm}^{3}\right)=1.7772 x+3.05195
$$

to the $\mathrm{X}$ ray density-composition data for $\mathrm{Fe}_{x} \mathrm{~S}$ [Robie et al., 1966] ( $x$ is the mole fraction of $\mathrm{Fe}^{++}$, here assumed to be 0.876 (weighted average) (Table 1)). Debye-Scherrer patterns of one of the crystals studied indicate that the pyrrhotite sample has monoclinic symmetry and demonstrates intensities more similar to those estimated by Corbett [1974], ATSM Cards 17-000 and $17-000 \mathrm{~A}$, than to those for other crystals previously studied.

For the purposes of measuring Hugoniot and release adiabat equation of state data, the samples were mounted on 2024 $\mathrm{Al}$ and $\mathrm{W}$ driver plates, $1.5 \mathrm{~mm}$ thick, in the case of shock compressions carried out on the $40-\mathrm{mm}$ gun apparatus; and 0.5-mm-thick, Ta driver plates in the case of the two light gas gun experiments (LGGI9 and LGG12, Table 3). Flat and inclined mirrors [Doran, 1963] were mounted on the sample assemblies in order to measure shock and free-surface velocities in the 40-mm gun experiments applying the techniques described by Ahrens et al. [1971, 1973]. The impedance-match method was used to obtain final shock states on the experiments using both apparati and employing shock wave data for the standard materials (2024 Al, W, and Ta) [McQueen et al., 1970]. In the 40-mm gun experiments in which a two-wave structure was detected, the particle velocity behind the first wave was obtained using the free-surface approximation [Walsh and Christian, 1955]. For the light gas gun experiments, sample assemblies employing only flat mirrors (soda-lime glass and fused quartz) to measure shock velocity through the sample and buffer material [Ahrens et al., 1969] were utilized 


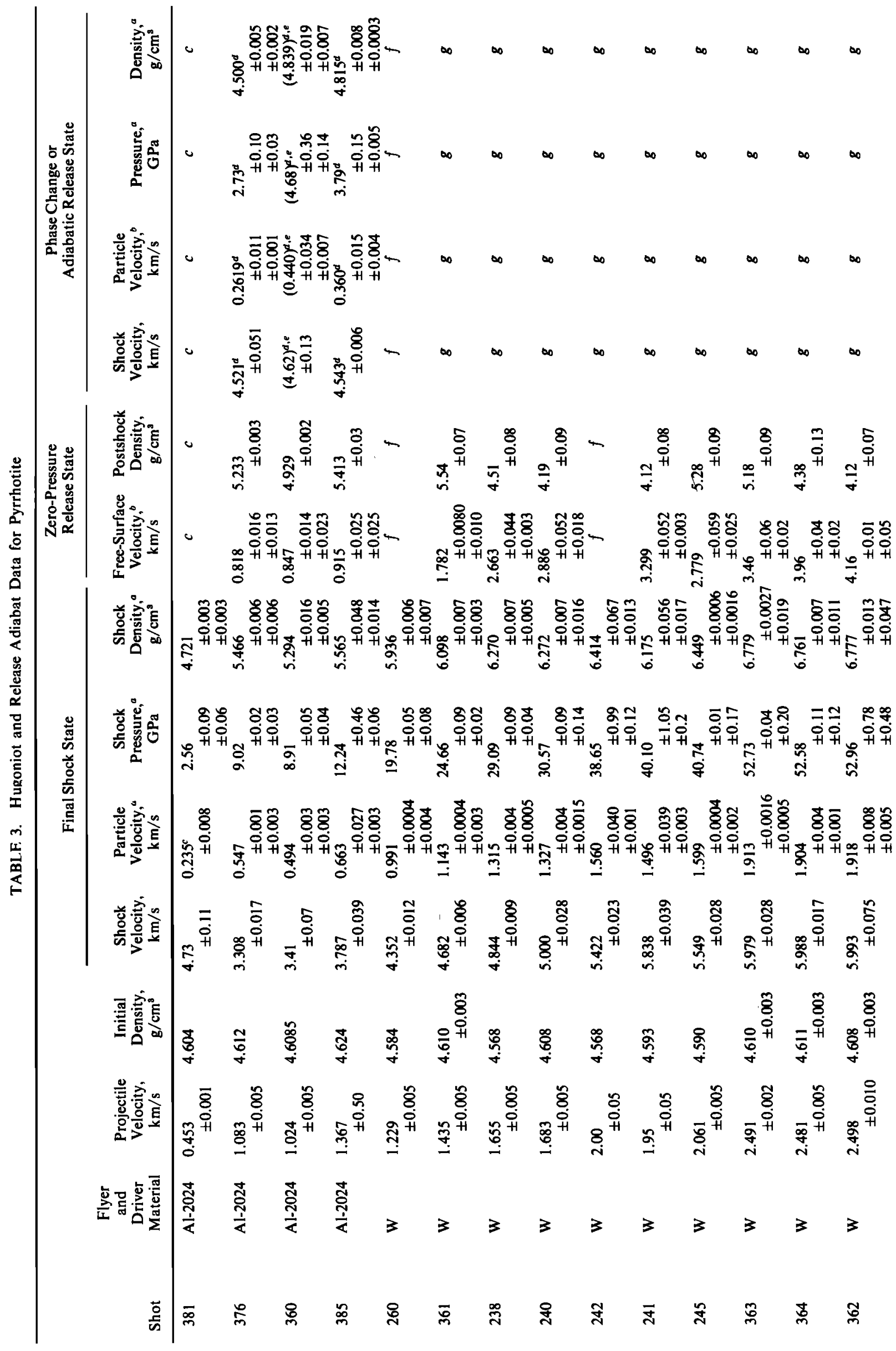




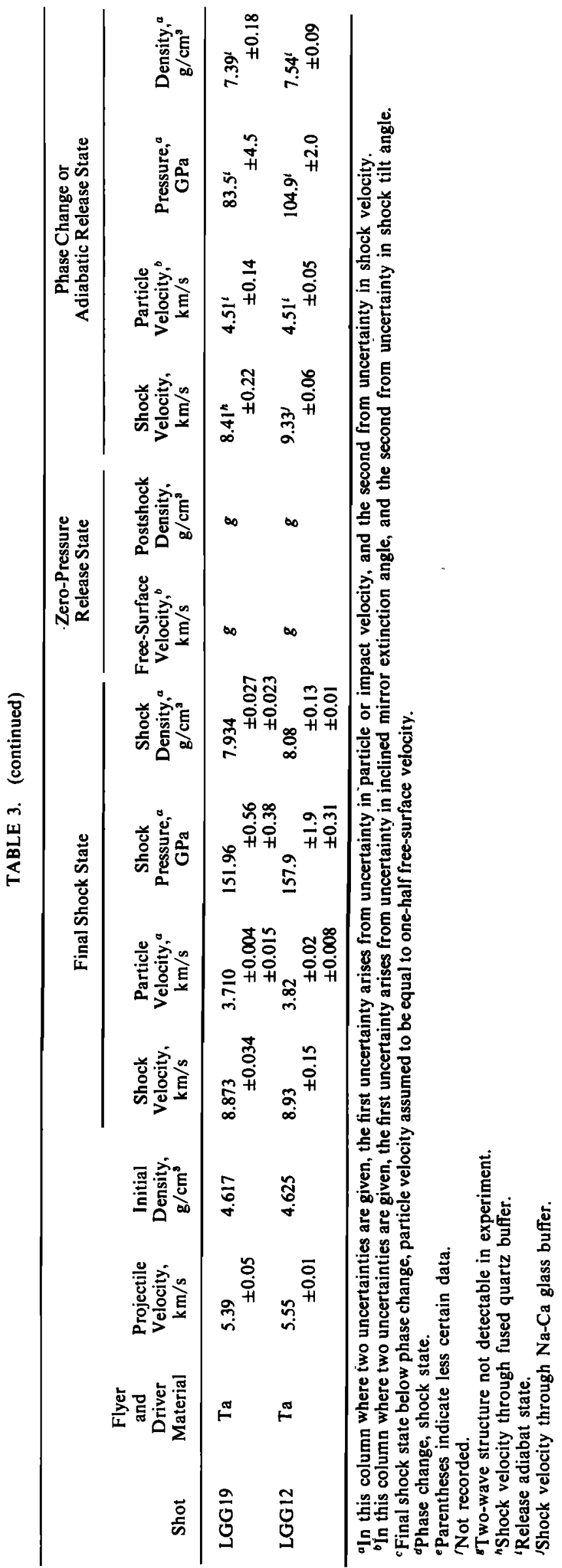

using the configuration described by Jeanloz and Ahrens [1977]. In the 40-mm experiments, 3.8- and 2.5-mm-thick 2024Al or polycrystalline, drawn W flyer plates imbedded in polycarbonate projectiles were used to impact the sample. In the light gas gun experiments the polycrystalline tantalum flyer plates were $2.5 \mathrm{~mm}$ thick, and projectile velocities were measured using the flash $\mathrm{X}$ ray timing techniques described by Jeanloz and Ahrens [1977]. In the 40-mm gun propellant apparatus the laser obscuration technique of Ahrens et al. [1971] was used to measure projectile velocity. Shock velocities were measured by determining the times at which specular reflection of the image of a xenon light source $(380 \mathrm{~J}$; rise time, 100 $\mu \mathrm{s})$ is extinguished upon interaction of the shock wave with the lapped driver plate-mirror or sample-mirror interfaces in the case of both guns. Although time resolutions of $\sim 2$ and $\sim 4 \mathrm{~ns}$ are, in principle, achievable at writing rates of 13 and $25 \mathrm{~mm} /$ $\mu \mathrm{s}$, using an image converter streak camera, uncertainties in interpreting changes in optical density on the film increased the uncertainties in shock velocity to the values quoted in Table 3, on a shot by shot basis. Time calibration of the streak camera writing rates to within $\pm 0.25 \%$ aré obtained using a Pockel's-cell modulated Ar-ion laser beam which provides 50ns timing marks [Jeanloz and Ahrens, 1977].

\section{Experimental Results for Pyrrhotite}

As demonstrated by the streak camera record shown in Figure 1, a very distinct double-wave structure was observed in three inclined mirror experiments [Ahrens et al., 1973] with final shock states below $12 \mathrm{GPa}$. On the basis of the slight variation of the first wave front shock wave velocity, which for the first four shots listed in Table 3 gives $4.60 \pm 0.09$ (std. dev.) $\mathrm{km} / \mathrm{s}$, and the observation that this is close to the average longitudinal velocity $(4.76 \mathrm{~km} / \mathrm{s}$ at $1.0-\mathrm{GPa}$ hydrostatic pressure) observed by $\mathbf{N}$. Christensen (private communication, 1972) in pyrrhotite, this wave structure is associated with either dynamic yielding (i.e., a Hugoniot elastic limit) or a shock-induced phase change, or possibly a combination of the two phenomena. The thermodynamic and equation of state constraints associated with shock-induced phase changes have been discussed by McQueen et al. [1967] and recently reviewed by Duvall and Graham [1977].

The amplitude range of the first shock wave, $2.7-4.7 \mathrm{GPa}$, is similar to that expected on the basis of the static experiments and appears likely to represent the $\mathrm{FeS}(\mathrm{I}) \rightarrow \mathrm{FeS}(\mathrm{III})[$ Pichulo et al., 1976] transition. Notably, only single-shock fronts are observed in shots 381 and 260 , with final shock states of 2.6 and $19.8 \mathrm{GPa}$. The marked increase in density for shock states immediately above the stress levels associated with the initial shock state in the range of 8.9-24.7 GPa, shots $260,385,360$, and 361 (Table 3) shown in Figure 2 and the associated data for the free-surface velocities strongly indicate that the doublewave structure represents a phase change. The variation in observed amplitude is probably the result of different sample orientations or the slight differences in stoichiometry and resultant $\mathrm{Fe}^{++}$vacant site ordering in different samples. The most striking evidence for shock-induced polymorphism above $4.7 \mathrm{GPa}$ is the anomalously low free-surface velocities $u_{f s}$ observed using inclined mirrors for shots $360,376,385$, and 361 , which are all considerably lower than twice the shock state particle velocity $u_{R H}$.

Assuming isentropic rarefaction from the high-pressure shock state, a constraint on the minimum postshock specific volume, $V_{0}^{\prime}$, may be obtained from the formula [Lyzenga and Ahrens, 1978] 


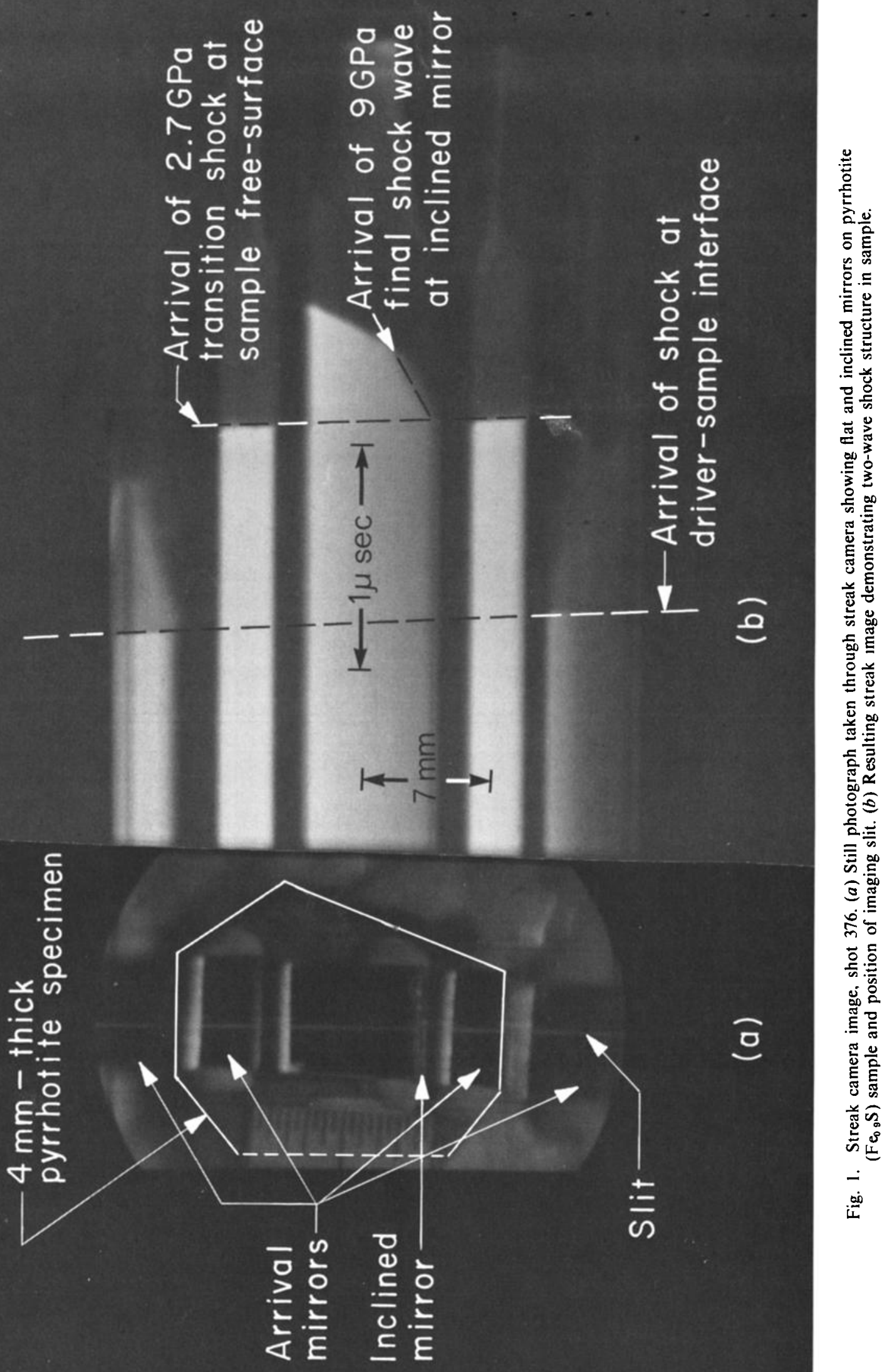




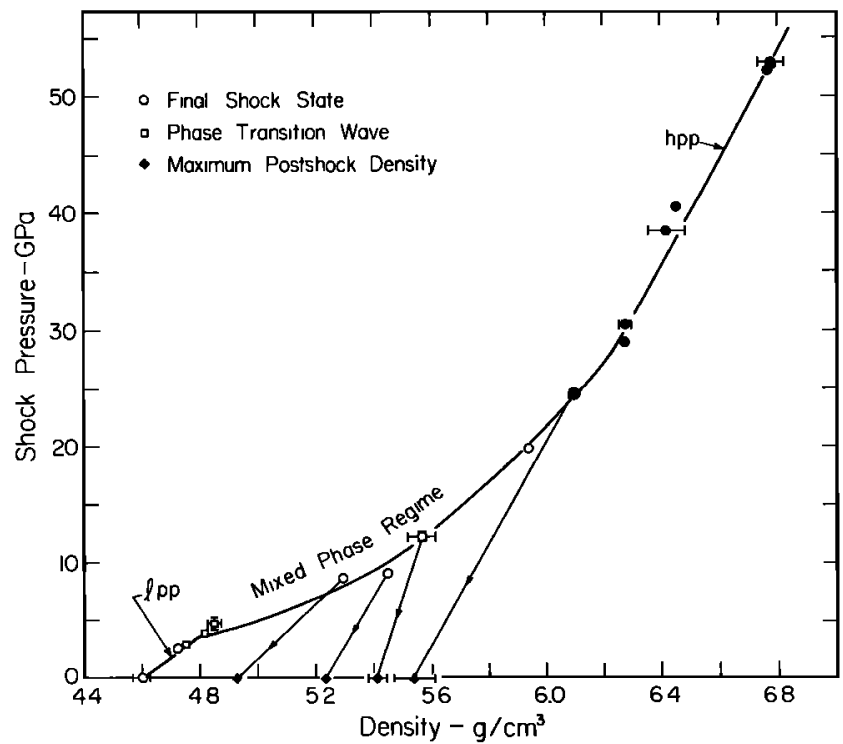

Fig. 2. Shock pressure versus density for Hugoniot and release wave data to $54 \mathrm{GPa}$ for pyrrhotite $\left(\mathrm{Fe}_{\mathrm{B} .8} \mathrm{~S}\right)$. Solid symbols are the same data points indicated in Figure 3. Shot 241 is omitted.

$$
V_{0}^{\prime}=V_{R H}+\frac{\left(u_{f s}-u_{R H}\right)^{2}}{P_{R H}}
$$

where $P_{R H}$ and $V_{R H}$ are the Hugoniot pressure and specific volume, respectively. The postshock density (the inverse of $\left.V_{0}^{\prime}\right)$ versus high-pressure shock density (Figure 4 ) provides a framework in which to interpret the Hugoniot data below 53.0 $\mathrm{GPa}$. If it is assumed that a transition from the defect $\mathrm{NiAs}$ structure of $\mathrm{Fe}_{0.8} \mathrm{~S}$ occurs in the $\sim 2.5$ - to 3.5-GPa range, presumably corresponding to the $\mathrm{FeS}(\mathrm{I})$ to $\mathrm{FeS}(\mathrm{IlI})$ transition of Pichulo et al. [1976], then the increase in maximum postshock density observed upon release from shock states in the 9.0- to 24.7-GPa range from 4.93 to $5.54 \mathrm{~g} / \mathrm{cm}^{3}$ can be understood. These data imply that successively larger quantities of $\mathrm{Fe}_{0.9} \mathrm{~S}$ are transforming from the low-pressure phase (lpp) to a high-pressure phase (hpp) and remain in the hpp upon pressure release (Figure 3). It should be emphasized that Lyzenga and Ahrens [1978] demonstrate that the postshock density calculated with (2) is only an upper bound; hence the postshock density values indicated in Figure 4 should be consid- ered semiquantitative. Above the $\sim 25-\mathrm{GPa}$ level the maximum postshock densities are rather scattered, but they nevertheless indicate successively lower postshock densities. This picture is consistent with the idea that upon release from higher shock pressures, incongruent melting followed probably by incongruent vaporization occurs. It thus appears that if one were interested in carrying out a shock recovery experiment possibly to obtain a sample of the hpp, shock loading to $\sim 25 \mathrm{GPa}$ would be an optimum pressure.

The detailed crystallographic nature of the hpp, or phases suggested by the large density increase under shock (Figure 2), double-shock structure (Figure 1), and the anomalously low free-surface velocities (Figure 4) are unknown. Densities for the hpp are estimated by King and Ahrens [1973], on the basis of bond length coordination number systematics, for an assumed eightfold coordinated structure with the pyrrhotite composition. These vary from 5.23 to $5.72 \mathrm{~g} / \mathrm{cm}^{3}$. This range not only encompasses the present maximum estimate of 5.54 $\mathrm{g} / \mathrm{cm}^{3}$ (shot 361 ) but is close to the value of $5.34 \mathrm{~g} / \mathrm{cm}^{3}$, which is inferred from assuming a $16 \%$ density increase from the lpp suggested by the density of $\mathrm{FeS}(\mathrm{IL})$ relative to $\mathrm{FeS}(\mathrm{I})$, troilite [Pichulo et al., 1976].

Arrival mirrors (fused quartz, $0.8 \mathrm{~mm}$ thick; and soda-lime glass, $1 \mathrm{~mm}$ thick) provided two approximate release adiabat data at 85 and $105 \mathrm{GPa}$ for the hpp of $\mathrm{Fe}_{0.8} \mathrm{~S}$, in the two light gas gun experiments (LGG19 and LGG12). The shock $\left(U_{s}\right)$ and particle $\left(u_{p}\right)$ velocity relations for the hpp regimes of the Hugoniots of fused quartz (initial density, $2.208 \mathrm{~g} / \mathrm{cm}^{3}$ ) and soda-lime glass (initial density, $2.49 \mathrm{~g} / \mathrm{cm}^{3}$ ) were taken as

$$
\begin{aligned}
& U_{s}=1.0740+1.6271 u_{p} \mathrm{~km} / \mathrm{s} \\
& U_{s}=2.608+1.490 u_{p} \mathrm{~km} / \mathrm{s}
\end{aligned}
$$

Equation (3) stems from fitting the Hugoniot data of Wackerle [1962], a datum $\left(U_{s}=11.42 \mathrm{~km} / \mathrm{s}, u_{p}=6.34 \mathrm{~km} / \mathrm{s}\right)$ given by Jones et al. [1968], and a new point $\left(U_{s}=8.18 \mathrm{~km} / \mathrm{s}, u_{p}=4.38\right.$ $\mathrm{km} / \mathrm{s}$ ) determined by observing shock propagation time through 2-mm-thick fused quartz driver plate mirrors on shot LGG19. As in the work of Jeanloz and Ahrens [1977], the time of self-illumination of the arrival mirrors was used to obtain the shock propagation time. (If, as suggested by $R$. $G$. McQueen (private communication, 1977), this illumination requires more than several ns to be visible or to decay in streak camera recordings, the resultant shock velocities will be sys-

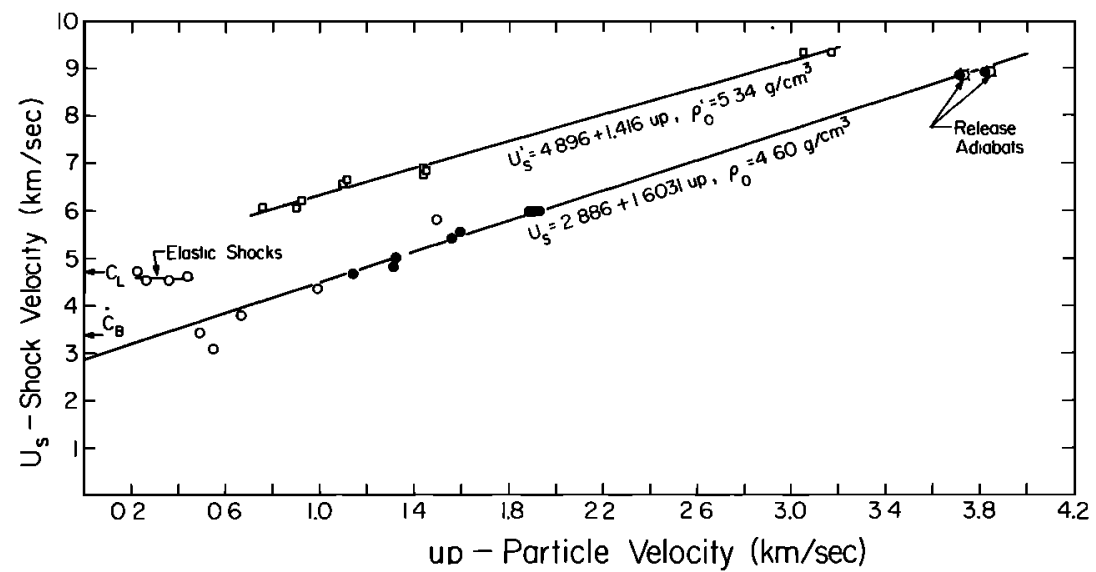

Fig. 3. Shock velocity versus particle velocity relation for pyrrhotite $\left(\mathrm{Fe}_{0} \mathrm{~g}\right)$. Open and solid circles indicate raw data; data indicated by solid circles have been used to fit straight line relation. Open circles with crosses indicate the equivalent shock and particle velocity values for high-pressure release adiabat states. Squares indicate the high-pressure phase pressure-volume data for which equivalent shock and particle velocity have been recentered, assuming an initıal zeropressure density of $5.34 \mathrm{~g} / \mathrm{cm}^{3}$. Values for $C_{L}$ and $C_{B}$ are from N. Christensen (private communication, 1972). 
tematically in error.) The data fit represented by (4) is taken from Jeanloz and Ahrens [1977]. The shock states in the buffer materials (both glasses) were reduced to pressure-density states using the approximation to the Riemann integral described by Ahrens et al. [1969]. The resulting pressure-density points are shown in Figure 5. If these release adiabat pressuredensity states were achieved via a shock transition, it is simple to calculate the corresponding shock and particle velocity values via the Rankine-Hugoniot relations. These are plotted in Figure 3. As is evident from the position of these two states in Figures 3 and 5 , they agree to within experimental uncertainties indicated in Table 3, with the Hugoniot curve either in the $U_{s}-u_{p}$ plane or the pressure-density plane. This apparent coincidence provides evidence that the light gas gun data, and most probably the $40-\mathrm{mm}$ gun data above $\sim 24 \mathrm{GPa}$, represent states in an hpp, which is assumed to be fluidlike in rheology. At what point the Hugoniot data in the high-pressure range for both $\mathrm{Fe}_{0.8} \mathrm{~S}$ and $\mathrm{FeS}_{2}$ (Figure 5) represent the behavior of a tightly packed liquid rather than a solid is unclear.

\section{Shock Wave Data and Conditions IN THE EARTH}

The temperatures within the earth's interior at core depths are poorly constrained. Recent estimates of the temperatures in the outer core range from 2 to $5 \times 10^{3} \mathrm{~K}$ [e.g., Kennedy and Higgins, 1972; Wang, 1972]. In spite of a lack of firm constraints on core temperatures it is important to carry out comparisons of density for various mixtures of $\mathrm{Fe}, \mathrm{Fe}_{0.8} \mathrm{~S}$, and $\mathrm{FeS}_{2}$ at the same temperature. For the present calculations, densities of various mixtures of iron and $h p p \mathrm{Fe}_{0.9} \mathrm{~S}$ and iron and hpp $\mathrm{FeS}_{2}$ are obtained by adding mass weighted specific volumes at constant pressure and temperature. The density, at a given pressure and calculated temperature, is constrained to the pressure-density relations obtained from free-oscillation inversions, and the mass fraction of sulfur is calculated. In essence, the Hugoniot and isothermal states are considered to be fluids, and ideal molar mixing is assumed. No correction for the volume change upon melting is assumed.

Even if the temperature $\left(T_{m}\right)$ at the core-mantle boundary were fairly well known, the variation of temperature within the core, $T_{c}$, depends directly on the equation of state $T(V)$ and the effective Grüneisen parameter, $\gamma$, according to

$$
T_{c}=T_{m} \exp \left[-\int_{V_{0 m}}^{V}(\gamma / V) d V\right]
$$

for a core with an adiabatic temperature gradient, where the specific volume at the core-mantle interface is $V_{0 m}$.

Recently, Jamieson et al. [1978] have pointed out that the available thermochemical and shock wave data for porous iron [Al'tshuler et al., 1958a; McQueen et al., 1970] indicate that the effective $\gamma$ for the regime of an iron core is in the range of 1.1-1.9. Stacey [1976] gives, on the basis of the seismic data, a mean value of $\gamma=1.4$ for the core; however, it is clear that the volume dependence of $\gamma$ is presently poorly defined [ $\mathrm{Mu}$ largia, 1977]. Grüneisen parameters in the range suggested by Jamieson et al. [1978] lead to large variations in the adiabatic temperature gradient in the outer core. For example, if $\gamma / V$ is assumed constant and the core-mantle interface is assumed to be at $3500^{\circ} \mathrm{K}$, temperature rises of $746^{\circ}-1386^{\circ} \mathrm{K}$ are obtained upon going from the base of the mantle to the base of the outer core, from (5) and the earth models of Gilbert and Dziewonski [1975] or Hart et al. [1977], for $\gamma$ (at the top of the core) of 1.1-1.9. Since such temperature gradients can be increased or decreased over even wider ranges by also varying the volume

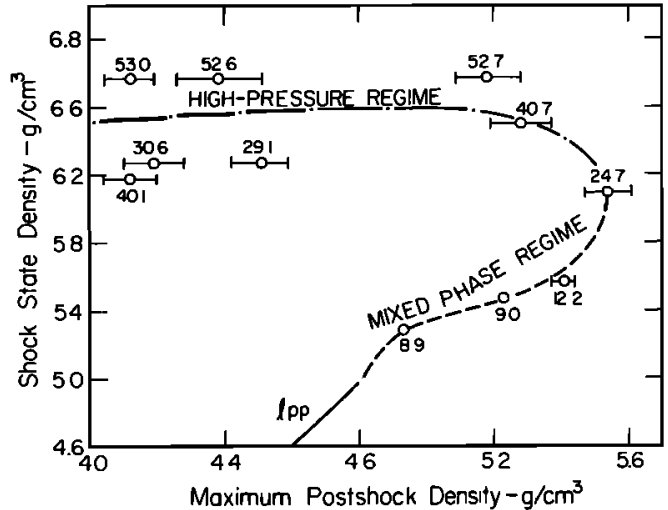

Fig. 4. Maximum postshock density versus shock state density for pyrrhotite $\left(\mathrm{Fe}_{0.8} \mathrm{~S}\right)$. Shock state density is determined from RankineHugoniot equations, whereas postshock density represents an upper bound calculated from an approximation to the Riemann integral [Lyzenga and Ahrens, 1978].

or temperature dependence of $\gamma$, at present it appears useful to attempt to calculate isotherms which are consistent with a wide range of possible equations of state. This tactic differs from that of Alder and Trigueros [1977], who have calculated detailed core models for density and sound speed based strictly on a Dugdale-McDonald value for the zero-pressure Grüneisen parameter [e.g., Rodean, 1977].

In addition to the new data for pyrrhotite discussed above, Simakov et al. [1974] have reported six new data points for pyrite, $\mathrm{FeS}_{2}$, (initial density, $4.91 \mathrm{~g} / \mathrm{cm}^{3}$ ) in the range $28.9-$ $319.5 \mathrm{GPa}$, which are also used in calculating several equation of state models.

\section{Reduction of Pyrite Shock Data}

Not unlike the results for pyrrhotite discussed in the previous section, Simakov et al's [1974] data indicate that a

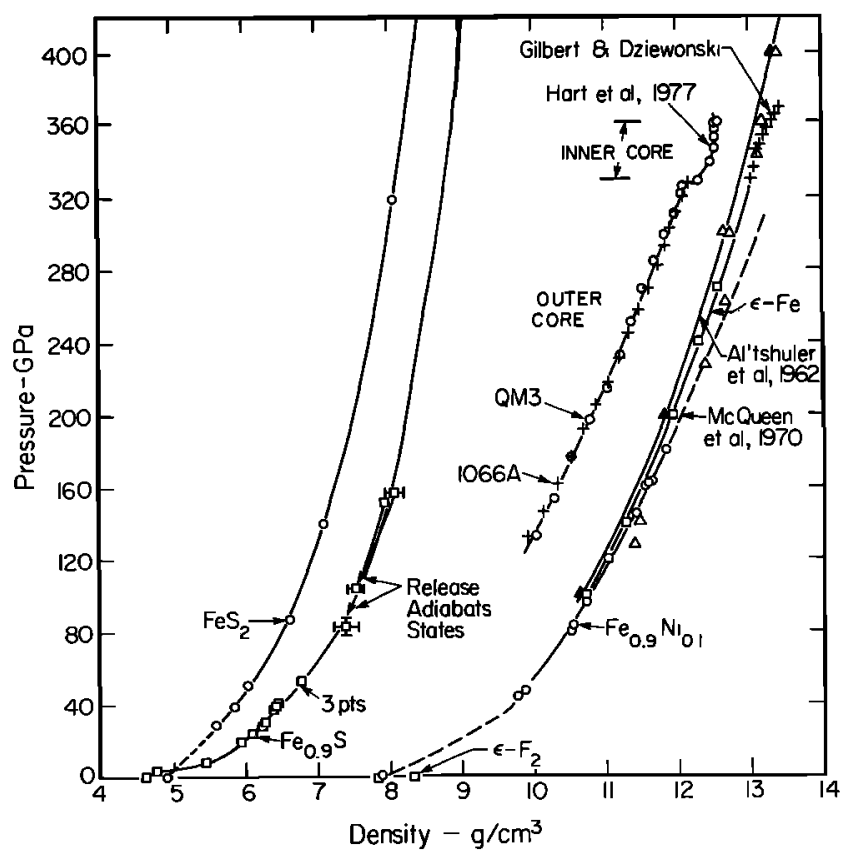

Fig. 5. Pressure versus density Hugoniot data for $\mathrm{FeS}_{2}$ (pyrite), [after Simakov et al., 1974], $\mathrm{Fe}_{0.8} \mathrm{~S}$ (pyrrhotite), and $\mathrm{Fe}$ and seismologically derived relations for the outer and inner cores of the earth. Solid triangles are smoothed Hugoniot data reported by Al'tshuler et al. [1962], whereas open triangles are raw data from Altshuler [1958a]. 
shock-induced phase transition occurs in $\mathrm{FeS}_{2}$. Aside from the large density increase upon compression, the evidence for this is rather definitive in that the same apparent shock velocity is measured for 'final shock states' at 28.9 and $38.5 \mathrm{GPa}$. Because the first wave arrival detected with the pin contactor techniques employed by Simakov et al. had a constant velocity, it is likely that a multiple-shock wave was present in their 28.9and 38.5-GPa experiments. The lower pressure value (28.9 $\mathrm{GPa}$ ) is taken as an approximation to the transition pressure to an hpp of unknown structure. This is not likely to be a finite strength elastic shock, both because of its high amplitude and because the velocity measured, $7.00 \mathrm{~km} / \mathrm{s}$, is significantly lower than the $8.72 \mathrm{~km} / \mathrm{s}$ observed by Simmons and Birch [1963] for longitudinal wave propagation along (001) in pyrite.

Notably, Clendenen and Drickamer [1966] did not observe any pelymorphism up to $\sim 26 \mathrm{GPa}$ at room temperature in static high-pressure $X$ ray experiments using solid pressure media. Their compression data appear to be rather consistent with other results, probably on account of the low mechanical strength of the sulfides. The Clendenen and Drickamer [1966] values of the bulk modulus (and its pressure derivative) agree remarkably well with Bridgman's [1949] static data as well as the ultrasonically measured bulk modulus of Simmons and Birch [1963]. It is assumed that Simakov et al.'s [1974] point at $50.7 \mathrm{GPa}$ lies in the mixed phase regime (presumably a mixture of lpp and hpp).

It appears likely that since the three highest pressure points lie along nearly a straight line in the $U_{s}-u_{p}$ plane, this segment of the Hugoniot (87.6-319.5 GPa) appears to represent the behavior of a shock-induced hpp, although other interpretations of the $\mathrm{FeS}_{2}$ data are possible. The three datum points fit the pressure-volume curve associated with the linear $U_{s}-u_{p}$ relation

$$
\begin{gathered}
U_{s}=C_{0}{ }^{\prime}+S^{\prime} u_{p} \\
P=\rho_{0}{ }^{\prime} C_{0}{ }^{\prime 2} \eta /\left(1-S^{\prime} \eta\right)^{2}
\end{gathered}
$$

Here $\eta=1-\left(\rho_{0}{ }^{\prime} / \rho\right)$, where $\rho_{0}{ }^{\prime}$, the apparent hpp initial density, is $\sim 5.3 \mathrm{~g} / \mathrm{cm}^{3}$. In this case, $S^{\prime}=1.52$, and $C_{0}{ }^{\prime}=6.34$ $\mathrm{km} / \mathrm{s}$. Using the tentative $5.3-\mathrm{g} / \mathrm{cm}^{3}$ value for the hpp density, the estimated transition pressure of $28.9 \mathrm{GPa}$, and the Clendenen and Drickamer [1966] pressure-volume data for $\mathrm{FeS}_{2}$, yields a transition energy of $\sim 0.38 \times 10^{10} \mathrm{erg} / \mathrm{g}$. This estimate has been used in subsequent shock wave reductions.

\section{REDUCTIONS TO PRINCIPAL IsENTROPES}

For the hpp of $\mathrm{Fe}_{0.8} \mathrm{~S}$, a linear shock-particle velocity relation fits the raw data extremely well. By including shot 361 and all higher pressure shots except for shot 241,10 data points fit the relation

$$
U_{s}(\mathrm{~km} / \mathrm{s})=1.603+2.886 u_{p}
$$

with a correlation coefficient value of 0.998 , assuming a mean zero-pressure density of $4.603 \mathrm{~g} / \mathrm{cm}^{3}$.

Principal isentropes, centered at STP, for the hpp of $\mathrm{Fe}_{0.8} \mathrm{~S}$ and $\mathrm{FeS}_{2}$ have been calculated using the fourth-order Eulerian finite strain formulation of Davies [1973] for the insentropic pressure $P_{s}$ :

$$
\begin{aligned}
P_{8}={ }_{2} K_{0} & \left\{( x ^ { 7 } - x ^ { 5 } ) \left[\left(1+\xi_{1}\right)-\right.\right. \\
& \left.\xi_{1} x^{2}\right] \\
& \left.+\xi_{2}\left(x^{7}-x^{5}\right)\left(x^{2}-1\right)^{2}\right\}
\end{aligned}
$$

Equation (9) may be integrated to give the energy along the isentrope,

$$
\begin{aligned}
E_{s}= & -\int_{V_{0}}^{v} P_{s} d V=\frac{9}{2} V_{0} K_{0}\left\{\left[\left(\xi_{1}+1\right)\right.\right. \\
& \left..\left(\frac{x^{4}}{4}-\frac{x^{2}}{2}+\frac{1}{4}\right)\right]-\left[\xi_{1}\left(\frac{x^{6}}{6}-\frac{x^{4}}{4}+\frac{1}{12}\right)\right] \\
& \left.+\xi_{2}\left[\frac{x^{8}}{8}-\frac{x^{6}}{2}+\frac{3 x^{4}}{4}-\frac{x^{2}}{2}+\frac{1}{8}\right]\right\}
\end{aligned}
$$

where $K_{0}$ is the zero pressure (adiabatic) bulk modulus, $x=$ $\left(V_{0} / V\right)^{1 / 3}$ (where $V_{0}$ and $V$ are the hpp zero-pressure and highpressure specific volumes), and

$$
\xi_{1}=\mathfrak{x}\left(4-K_{0}{ }^{\prime}\right)
$$

where $\left.K_{0}^{\prime} \equiv\left(\partial K_{0} / \partial P\right)\right|_{P=0}$ is the pressure derivative of the adiabatic bulk modulus at zero pressure. Also

$$
\xi_{2}={ }_{9}^{9} K_{0} K_{0}^{\prime \prime}+{ }_{8}^{9} K_{0}{ }^{\prime}\left(K_{0}^{\prime}-7\right)+(143 / 24)
$$

where $\left.K_{0}{ }^{\prime \prime} \equiv\left(\partial K_{0}{ }^{\prime} / \partial P\right)\right|_{P=0}$. The often used Birch-Murnaghan equation of state [Birch, 1952] is a special case of (9), where $\xi_{2}$ $=0$. Notably, it is evident from (12) that this so-called thirdorder Birch-Murnaghan equation prescribes a nonzero value of $K_{0}^{\prime \prime}$ for $\xi_{2}=0$.

Theoretical pressure $\left(\boldsymbol{P}_{H}\right)$-volume Hugoniot states can be calculated using (9)-(11) in either the full fourth-order or the Birch-Murnaghan form from

$P_{H}=\left(E_{s}-P_{s} V / \gamma+E_{T R}\right)\left[\left(V_{00}-V\right) / 2-V / \gamma\right]^{-1}$

where $E_{T R}$ is the transition energy from the lpp to the hpp and $V_{\infty 0}$ is the zero-pressure specific volume of the lpp. Equation (13) is obtained by combining the Rankine-Hugoniot energy conservation equation with the Mie-Grüneisen equation of state. Although the simplifying assumption that $\gamma / V$ is a constant is made, the range of zero-pressure $\gamma$ examined, for example, in the case of the hpp of $\mathrm{Fe}_{0.8} \mathrm{~S}$, varied from 1.0 to 2.5 , and initial densities varied from 5.33 to $5.46 \mathrm{~g} / \mathrm{cm}^{3}$. In the case of $\mathrm{FeS}_{2}$ the small data set precluded attempting to obtain separately a best fit for zero-pressure density and Grüneisen parameter; however, the latter was varied from 1.4 to 2.5. Best fits for the shock wave data, in terms of principal isentropes for both the fourth-order, Eulerian, finite strain equation and the Birch-Murnaghan equation are given in Table 4.

Since it has long been recognized that there is physically no unique basis for developing various finite strain formulae [e.g., Knopoff. 1960], it is appropriate to examine the data for both $\mathrm{Fe}_{0.9} \mathrm{~S}$ and $\mathrm{FeS}_{2}$ in terms of another equation of state framework. A convenient pressure-volume curve to represent an isentrope is (7). If (7) represents an isentrope, it may be integrated to yield the energy as

$E_{s}-\int_{V_{0}}^{V} P d V=\left(C_{0}^{\prime} / S^{\prime}\right)^{2}\left[\frac{S^{\prime} \eta}{1-S^{\prime} \eta}+\ln \left(1-S^{\prime} \eta\right)\right]$

The above assumptions imply that the raw Hugoniot data do not satisfy (6). The use of (7) and (14) also permits straightforward application of the Slater $(n=0)$, Dugdale-McDonald $(n=\mathbf{3})$, and free-volume $(n=\mathbf{z})$ formulae for the zero-pressure value of Grüneisen parameter $\gamma_{0}$, which can succinctly be written as [e.g., Rodean, 1977]

$$
\gamma_{0}=2 S^{\prime}-3-\frac{1}{2} n
$$

By linking the Grüneisen parameter directly to $S^{\prime}$, which in the case of the Murnaghan equation of state is related to $K_{0}^{\prime}$ by [Ruoff, 1967] 
TABLE 4. Equation of State Parameters for Principle Isentropes, $\mathrm{Fe}_{\mathrm{og} \text { gre }} \mathrm{S}$ (hpp) and $\mathrm{FeS}_{2}$ (hpp)

\begin{tabular}{|c|c|c|c|c|c|c|}
\hline & $\rho_{0}, \mathrm{~g} / \mathrm{cm}^{3}$ & $K_{0}, \mathrm{GPa}$ & $K_{0}^{\prime}$ & $K_{0}^{\prime \prime}, \mathrm{GPa}^{-1}$ & $\gamma$ & $E_{\mathrm{TR}}, 10^{10} \mathrm{erg} / \mathrm{g}$ \\
\hline $\begin{array}{l}\mathrm{Fe}_{0.878} \mathrm{~S} \\
\mathrm{FeS}_{2}\end{array}$ & $\begin{array}{l}5.3389 \\
5.3\end{array}$ & $\begin{array}{l}\text { Fourth- } \\
128 \\
216\end{array}$ & $\begin{array}{l}\text { Euleria } \\
3.332 \\
4.4\end{array}$ & $\begin{array}{l}\text { ation of State } \\
+0.205 \\
0.0\end{array}$ & $\begin{array}{l}1.3 \\
1.4\end{array}$ & $\begin{array}{l}0.097 \\
0.377\end{array}$ \\
\hline $\begin{array}{l}\mathrm{Fe}_{0878} \mathrm{~S} \\
\mathrm{FeS}_{2}\end{array}$ & $\begin{array}{l}5.33 \\
5.3\end{array}$ & $\begin{array}{l}\quad \text { Birch } \\
125.8 \\
205\end{array}$ & $\begin{array}{l}\text { naghan } \\
4.833 \\
4.9\end{array}$ & $\begin{array}{c}\text { of of State } \\
-0.0430 \\
-0.0273\end{array}$ & $\begin{array}{l}2.5 \\
2.0\end{array}$ & $\begin{array}{l}0.0967 \\
0.377\end{array}$ \\
\hline & $\rho_{0}, \mathrm{~g} / \mathrm{cm}^{3}$ & $K_{0}, \mathrm{GPa}$ & $S^{\prime}$ & $\gamma$ & & $E_{T R}, 10^{10} \mathrm{erg} / \mathrm{g}$ \\
\hline $\begin{array}{l}\mathrm{Fe}_{0878} \mathrm{~S} \\
\mathrm{FeS}_{\mathrm{g}}\end{array}$ & $\begin{array}{l}5.3389 \\
5.3\end{array}$ & $\begin{array}{c}\text { Shock } W a \\
125.9 \\
243.9\end{array}$ & $\begin{array}{l}\text { uation o. } \\
1.193 \\
1.245\end{array}$ & $\begin{array}{c}\text { Linear, } U_{s} \\
1.053 \\
1.157\end{array}$ & & $\begin{array}{l}0.098 \\
0.377\end{array}$ \\
\hline
\end{tabular}

$$
S^{\prime}=\left(K_{0}^{\prime}+1\right) / 4
$$

provides a reduction of the number of parameters and hence an objective comparison of the three different formulae for the Grüneisen parameter. In constructing theoretical Hugoniots from (14) for both $\mathrm{Fe}_{0.8} \mathrm{~S}$ and $\mathrm{FeS}_{2}$, increasingly better fits are obtained as $n$ is increased from zero (Slater) to ? (Dugdale$\mathrm{McDonald}$ ) to $f$ (the free volume of Vaschenko and Zubarev [1963] or Irvine and Stacey [1975]) formulation of $\gamma$. Principal isentropes which best predict the Hugoniot data with the freevolume $\gamma$ are quoted in Table 4.

\section{OTHER SULFIDES}

Until recently, geophysically motivated equation of state studies have focused largely on the metals, oxides, and silicates. Since the sulfides have received little attention in this regard, it is interesting to examine the present data for the hpp of pyrrhotite and, to a limited extent, the hpp of $\mathrm{FeS}_{2}$ in the context of the expected dependence of bulk moduli or sound speed on mean atomic volume.

A simple assumption is that all of the bulk moduli or bulk sound speeds of the sulfides are controlled by the same interatomic repulsion parameter of the form

$$
E \propto \exp \left(-\alpha x^{1 / 3}\right)
$$

where $E$ is the lattice energy, $x$ is relative volume $V / V_{0}$ or relative density $\rho_{0} / \rho$, and $\alpha$ is an average repulsion parameter. We infer from their electrical properties that the sulfides are either strongly covalently or metallically bonded. Upon differentiation of (17) twice with respect to density, expansion of the resulting expression about $x \approx 1.0$, and squaring of the result to obtain an expression proportional to sound speed, a polynomial up to fourth order in $x$ and a sixth-order polynomial in $\alpha$ are obtained. If the bulk sound velocities of the sulfides are calculated using the data collected by Birch [1966] (largely Bridgman's [1949] static compression measurements) and the ultrasonic data of Simmons and Wang [1971], a linear, rather than higher-order, relation of the form

$$
C_{0}(\mathrm{~km} / \mathrm{s})=7.15-0.47 \bar{V}
$$

where $\bar{V}$ is the mean atomic volume, fits the available data better than relations which employ either the mineral densities or the bulk moduli [e.g., Anderson, 1967; Anderson and Anderson, 1970]. As indicated in Figure 6, (18) does not fit the data for two polymorphs of $\mathrm{Ag}_{2} \mathrm{~S}$ (argentite and acanthite). These minerals have a lower coordination number with $S$ than that of most of the other minerals. The mineral, bismuthinite $\left(\mathrm{Bi}_{2} \mathrm{~S}_{3}\right)$ does not fit the trend of the other data well, perhaps because of its high mean atomic weight, 102.8. However, the bulk sound speed of $\mathrm{PbS}$ (galena), which has a mean atomic weight of 119.6, fits (18). The mineral arsenopyrite, FeAsS, is a marginal case.

As is evident in Figure 6, the present result for the sound speed of the hpp of $\mathrm{FeS}_{2}$ is significantly above the value predicted by (18), whereas the sound speed of the hpp of $\mathrm{Fe}_{0.9} \mathrm{~S}$ lies somewhat below the (18) value. Considering the, at present, weak theoretical basis of the systematics displayed by Figure 6, this relation should not be used as a constraint in reducing shock wave data. It is interesting that Scolt [1973] has discovered that many of the same sulfides plotted in Figure 6 demonstrate a good correlation of Vickers hardness and compressibility. Hardness fundamentally involves shear modulus, or strength, and density, whereas the compressibility is, of course, simply related to bulk sound speed.

\section{ISOTHERMAL EQUATIONS OF STATE}

Using the principal isentropes calculated by the method outlined in the section on reduction to principal isentropes, a series of pressure-density isotherms are easily calculated by first calculating the temperature along the principal isentropes

$$
T_{s}=T_{0} \exp \left[-\frac{\gamma}{V} \int_{V_{0}}^{V} d V\right]
$$

where $T_{0}$ is room temperature. Then at a given specific volume

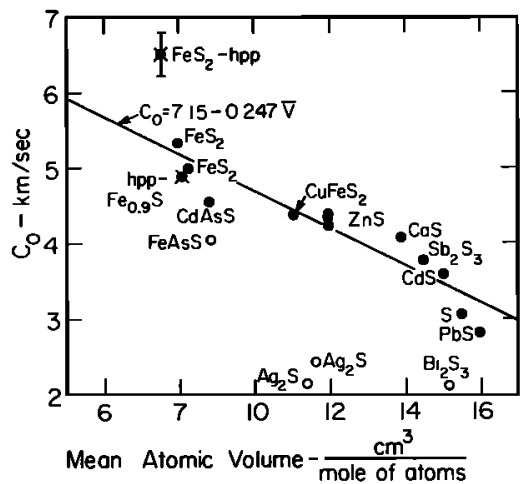

Fig. 6. Zero-pressure bulk sound speed, $C_{0}$, versus volume per mole of atoms for sulfides and elemental sulfur. Solid symbols indicate datum points to which a straight line relation has been fit. Values for hpp $\mathrm{Fe}_{0 . \mathrm{g}} \mathrm{S}$ and hpp $\mathrm{FeS}_{2}$ correspond to range of reduced shock wave data given in Table 4. 


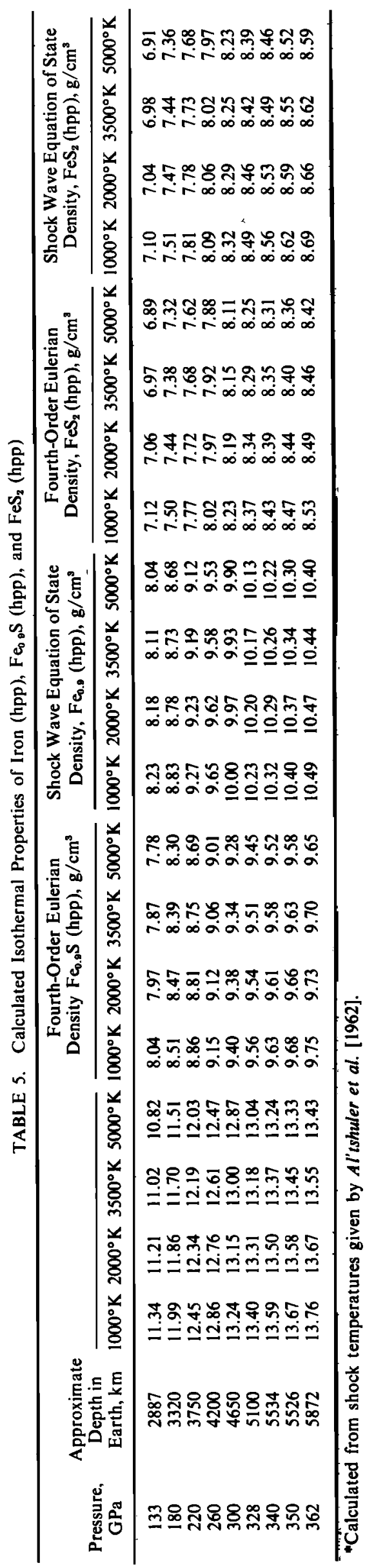

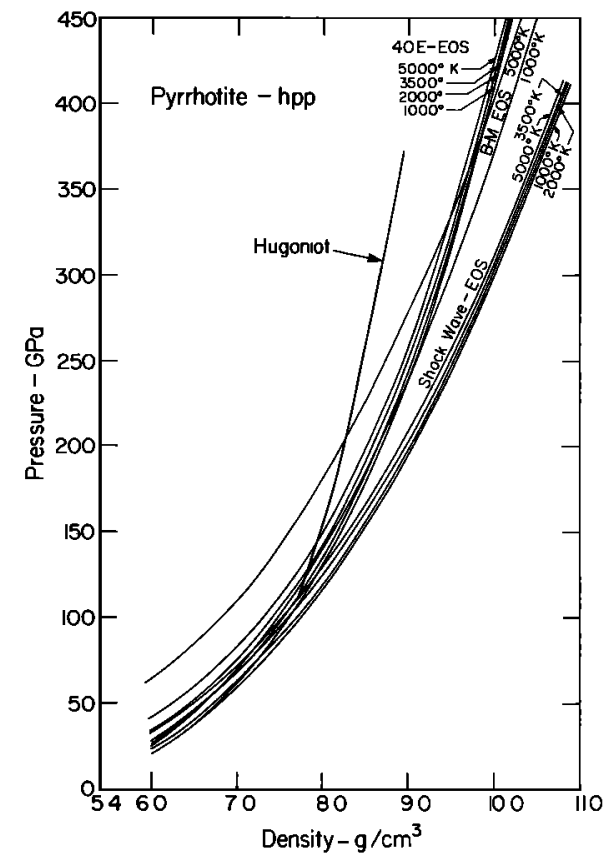

Fig. 7. Calculated isotherms and Hugoniot curve for $\mathrm{Fe}_{0.9} \mathrm{~S}$ (pyrrhotite) hpp. Parameters of principal isentropes corresponding to isotherms shown for fourth-order Eulerian finite strain equation of state (4OE), Birch-Murnaghan equation of state (B-M EOS), and shock wave equation of state (SWEOS) are given in Table 4

the pressure associated with the isotherm (of temperature $T$ ) is calculated using

$$
P_{T}=P_{s}+\frac{\gamma}{V} \int_{T_{s}}^{T} C_{v} d T
$$

The specific heat value $C_{v}$ used in calculating the isotherms listed in Table 5 and shown in Figures 7 and 8 corresponds to $\bar{M} C_{V} / R=3$, whereas the value used by Alder and Trigueros

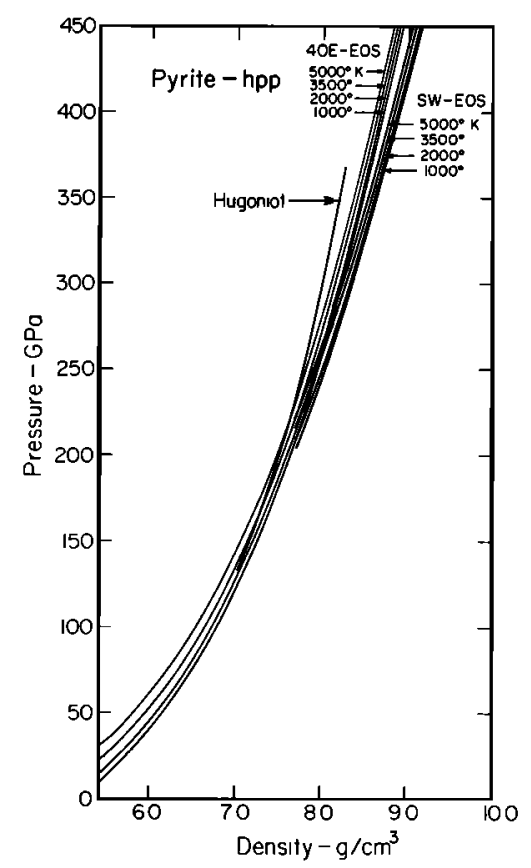

Fig. 8. Calculated isotherms and Hugoniot curves for $\mathrm{FeS}_{2}$ (pyrite) hpp. Parameters of principal isentropes for shock wave (SW) and fourth-order Eulerian (4OE) equations of state corresponding to these isotherms are given in Table 4. 
[1977] of 2.72 may be more realistic in light of the systematic decrease observed in specific heat of metals upon melting [Grover, 1971] (if the sulfides are melted in the temperature and pressure range of interest). Here $\bar{M}$ is the mean atomic weight, and $R$ the gas constant. Extremum sets of isotherms are shown in Figures 7 and 8 for $\mathrm{Fe}_{0.9} \mathrm{~S}$ and $\mathrm{FeS}_{2}$, demonstrating that the variation in both the form of the equation of state and the value of the Grüneisen parameters give rise to a considerable range of calculated isotherms. If the Mie-Grüneisen formulation is grossly invalid, even larger uncertainties in these reductions may result.

In the case of the shock data for iron, the differences between two independent data sets and shock wave reductions [Al'tshuler et al., 1958a, b, 1962; McQueen et al.. 1970] are not excessive, although the Hugoniot densities differ by $\sim 0.1 \mathrm{~g} /$ $\mathrm{cm}^{3}$ at $250 \mathrm{GPa}$. For both data sets the isotherms shown in Figure 9 were calculated on the basis of theoretical Hugoniot temperatures quoted by Al'tshuler et al. [1962] and McQueen et al. [1970] using the slightly different assumptions underlying the two different reductions. In calculating isotherms corresponding to the Al'tshuler et al. [1962] data, rather than using a Grüneisen parameter which is dependent only on volume via the Dugdale-McDonald relation, an attempt is made to take into account anharmonicity of the thermal vibrations via theoretical calculations of the volume and a mean temperature dependence of the specific heat and Grüneisen parameter (both decrease slightly with temperature) via the dimensionless parameter

$$
\theta=R T \rho_{0^{\circ} K} /(3 Q \bar{M})
$$

where $\rho_{0}{ }^{\circ} \mathrm{K}$, the zero pressure and temperature density of $\epsilon$ iron, is $9.42 \mathrm{~g} / \mathrm{cm}^{3}$ and $Q=95.44 \mathrm{GPa}$, a parameter in the assumed form of the $0^{\circ} \mathrm{K}$ isothermal equation of state

$P_{0^{\circ} K}=A\left(\frac{\rho}{\rho_{0^{\circ} K}}\right)^{2 / 3} \exp \left[-B\left(\frac{\rho_{0^{\circ} K}}{\rho}\right)^{1 / 3}\right]-Q\left(\frac{\rho}{\rho_{0^{\circ} K}}\right)^{4 / 3}$

Here $A$ and $B$ are constants which are fit to the data.

Although the Al'tshuler et al. formulation takes into account the electronic contribution to the thermal Grüneisen parameter, $\gamma_{e}=1.5$, since it is nearly numerically equal to the lattice Grüneisen parameter, the resultant thermal equation of state is little affected [e.g., Jamieson et al., 1978]. In calculating isotherms from the Hugoniot temperatures quoted by $M c Q u e e n$ et al. [1970], the assumptions that $(\partial E / \partial P)_{V}$ is a constant and that $M C_{V} / R=3$ were used. Although the Al'tshuler et al. approach is more complicated, the calculated isotherms from McQueen et al.'s data are denser by $\sim 0.15 \mathrm{~g}$ / $\mathrm{cm}^{3}$ at $5000^{\circ} \mathrm{K}$ and $250 \mathrm{GPa}$ than those calculated from Al'tshuler et al's [1962] reduction. This difference is comparable in magnitude to the difference in density between the Hugoniots of pure iron and $\mathrm{Fe}_{0.8} \mathrm{Ni}_{0.1}$ measured by McQueen and Marsh [1966] (Figure 5).

\section{Constraints on the Sulfur Content OF THE CORE}

Superimposed on the uncertainties of the calculated isotherms for hpp $\mathrm{Fe}_{0.8} \mathrm{~S}$, hpp $\mathrm{FeS}_{2}$, and $\mathrm{Fe}$ demonstrated by Figures 7-9, some uncertainties also exist in the exact distribution of mass in the outer and inner core of the earth. As seen in Figure 5, the results of Gilbert and Dziewonski [1975] (e.g., model 1066A) and those of Hart et al. [1977], and Hart [1977] (e.g., model QM-3) for the density distribution in the outer core are virtually identical. However, the absolute density can be resolved within only a relative error of $1 \%$ over a radius range of $\sim 475 \mathrm{~km}$ within the inner core, decreasing to $\sim 300$ $\mathrm{km}$ in the outer core [Gilbert et al., 1973] from inversion of free-oscillation data. Hence the average inner core density can, in principle, be resolved to within $\sim 0.1-0.2 \mathrm{~g} / \mathrm{cm}^{3}$ and to within $\sim 0.4 \mathrm{~g} / \mathrm{cm}^{3}$ in the outer core over the above radius ranges. The resolution of the free-oscillation data indicates that the agreement between the exact distribution of mass in the outer core between the two models shown in Figure 5, which both closely satisfy essentially the same data, is very close in the outer core and that the difference exhibited between two models such as 1066A and QM3 is a factor of 2 or 3 greater than expected for the inner core. The latter difference is not as significant, as the inner core represents only some $5 \%$ of the core mass. The discrepancy is likely an artifact of the starting models used in the inversion procedure (D. L. Anderson, private communication, 1978).

If the raw Hugoniot data are used to infer an approximate $S$ content of the core, Table 6 demonstrates that the data for both hpp $\mathrm{Fe}_{0.8} \mathrm{~S}$ and hpp $\mathrm{FeS}_{2}$ indicate a systematic decrease in $S$ content with depth in the outer core from $\sim 10$ to $\sim 5 \%$. This conclusion, which is difficult to reconcile with the hypothesis that the outer core is a convecting all-liquid system, is similar to that reached by Usselman [1975b]. This is demonstrated below to be an artifact of the higher compressions and hence higher shock temperatures achieved by $\mathrm{Fe}_{0.8} \mathrm{~S}$ and $\mathrm{FeS}_{2}$ than by $\mathrm{Fe}$ at a given pressure.

The extrema solutions for the $3500^{\circ}$ and $5000^{\circ} \mathrm{K}$ isotherms represented by description in terms of the shock wave equation of state (equation (7)) and the fourth-order finite strain relations (equation (9)) have been used to calculate apparent $S$ contents using the QM-3 [Hart, 1977] density distribution in the inner and outer core and the reduced shock wave data for

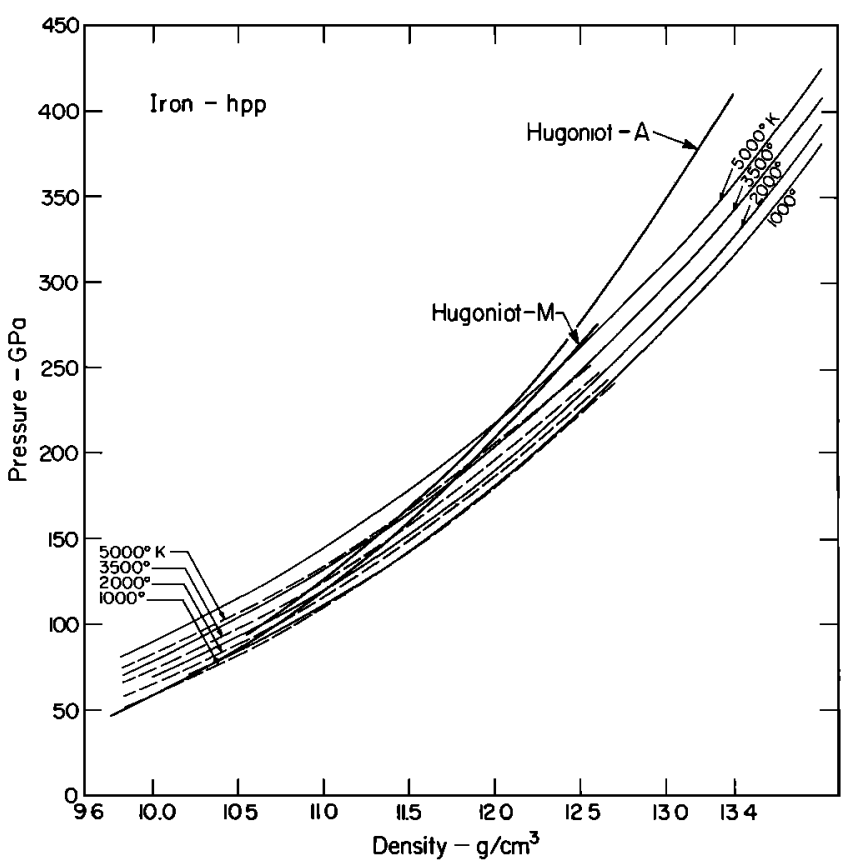

Fig. 9. Hugoniot and calculated isotherms for iron hpp. Hugoniot-M and dashed isotherms correspond to shock state temperatures given by McQueen et al. [1970], whereas Hugoniot-A and solid isotherms correspond to shock state temperatures given by Al tshuler et al. [1962]. 
TABLE 6. Sulfur Content Inferred From Raw Hugoniot Data

\begin{tabular}{cccc}
\hline $\begin{array}{c}\text { Pressure, } \\
\mathrm{GPa}\end{array}$ & $\begin{array}{c}\text { Core Density, } \\
\mathrm{g} / \mathrm{cm}^{3}\end{array}$ & $\begin{array}{c}\text { hpp Fe } \mathrm{FS}, \\
\text { wt \% S }\end{array}$ & $\begin{array}{c}\text { hpp FeS } \\
\text { wt \% S }\end{array}$ \\
\hline \multicolumn{4}{c}{ Outer Core } \\
133 & 10.00 & 10.4 & 10.1 \\
180 & 10.59 & 9.2 & 9.2 \\
220 & 11.03 & 8.0 & 8.2 \\
260 & 11.48 & 6.6 & 7.0 \\
300 & 11.86 & 5.8 & 6.1 \\
328 & 12.13 & 5.1 & 5.5 \\
\multicolumn{4}{c}{ Inner Core* } \\
340 & 12.47 & 3.2 & \\
350 & 12.53 & 3.2 & 3.5 \\
362 & 12.55 & 3.6 & 3.5 \\
\end{tabular}

*Density model from Hart [1977].

iron of Al'tshuler et al. [1962] for Fe (Figure 10). It is clear from Figure 5 that the denser inner core for model 1066A of Gilbert and Dziewonski [1975] is compatible with either a pure iron or possibly an iron-nickel core. Detailed reduction of the $\mathrm{Fe}_{0.8} \mathrm{Ni}_{0.1}$ Hugoniot data of McQueen and Marsh [1966] has not been carried out. Trial calculations for a Fe-S, 0.10 mole fraction Ni mixture demonstrate that, over the pressure range (130 to $180 \mathrm{GPa}$ ), only a $\sim 0.1 \%$ increase of $S$ content of the $\mathrm{Fe}-\mathrm{S}-\mathrm{Ni}$ mixture is required to satisfy the core density relative to a mixture of $\mathrm{S}$ with pure iron. The composition $\mathrm{Fe}_{0.9} \mathrm{Ni}_{0.1}$ studied by $M c Q$ ueen and Marsh [1966] is compatible with, but slightly more nickel rich than, the nickel contents of most siderites, as well as the composition calculated for equilibrium condensation of iron with nickel from the solar nebulae [Grossman, 1972]. Ringwood [1966] has argued that because of the relatively high $\mathrm{Ni}$ content of rocks differentiated from the mantle [Ringwood and Keeson, 1977] and the fact that the mole fraction of nickel to iron in the sun and carbonaceous chondrites is $\approx 0.05-0.06$ [Ross and Aller, 1976], the core is not required to contain $\mathrm{Ni}$ as a major alloying element.

Figure 10 demonstrates that the inferred $S$ content of the outer core depends slightly on both the assumed equation of state of the iron sulfide component and the assumed temperature. A fourth-order finite strain fit to the hpp $\mathrm{Fe}_{0.8} \mathrm{~S}$ data for a temperature of $\sim 3500^{\circ} \mathrm{K}$ in the uppermost outer core going to $5000^{\circ} \mathrm{K}$ at the outer core-inner core boundary indicates an $S$ content between $\sim 10.5$ and $\sim 9 \%$, whereas the shock wave equation of state solution, with a somewhat lower Grüneisen parameter for $\mathrm{Fe}_{0.9} \mathrm{~S}$, yields $\mathrm{S}$ contents in the range 12-10.5 wt $\%$. The $\mathrm{S}$ contents inferred from the $\mathrm{FeS}_{2}$ data are slightly lower, averaging $9.5-\sim 8.0 \%$ throughout the outer core. The latter should be considered a less reliable result. The agreement between the fourth-order and shock wave equation of state formulations is, probably fortuitously, much closer for $\mathrm{FeS}_{2}$. The large gradient in $\mathrm{S}$ content of the outer core obtained upon combining the new shock wave data for $\mathrm{Fe}_{0.8} \mathrm{~S}$, $\mathrm{FeS}_{2}$, and $\mathrm{Fe}$ is seen virtually to disappear within the present uncertainties in shock wave reductions. These results, which are based strictly on density compressions, are quite different from those recently obtained by Alder and Trigueros [1977], who have obtained theoretical sound speeds in the core by adding sound speeds weighted by mole fractions. The Alder and Trigueros [1977] analysis yields 3.9-4.7 wt \% S, based on their assumed linear $U_{s}-u_{p}$ relation and Dugdale-McDonald equations of state for the hpp's of Fe and FeS. They give 0.91 and $0.93 \mathrm{~mol}$ fraction $\mathrm{Fe}$, respectively, in the outer core for different assumed temperatures. The analysis applied in the present paper is specifically designed to circumvent the assumptions of the Walsh and Christian [1955] equations, which were used by Alder and Trigueros [1977]. In the Walsh and Christian [1955] formulation, shock heating results only from material compression, whereas in the present paper (and in the analysis of King and Ahrens [1973]) the Walsh and Christian [1955] assumptions have been modified to allow a substantial contribution of the thermal energy in the shock state to arise from the density changes associated with the phase change in $\mathrm{Fe}_{0.8} \mathrm{~S}$.

\section{Discussion}

If the sulfur content of the earth's core were in the range 912 wt \% as implied by the above analysis for $\mathrm{Fe}_{0.8} \mathrm{~S}$, it is of interest to examine the sulfur budget of the earth relative to the present solar photosphere and CC1 carbonaceous chondrites to determine whether the earth might, in light of the considerations summarized in the Introduction and Background section, still be depleted in sulfur. According to Ross and Aller [1976] the best estimate of the $\mathrm{Si} / \mathrm{S}$ atomic ratio for the sun is 2.82. The uncertainties are large; the maximum and minimum values for this ratio are 4.15 and 1.91 , respectively. These values compare remarkably well to the $\mathrm{Si} / \mathrm{S}$ ratio in $\mathrm{CCl}$ carbonaceous chondrites of 2.00 . Similarly, the Fe/S ratio of

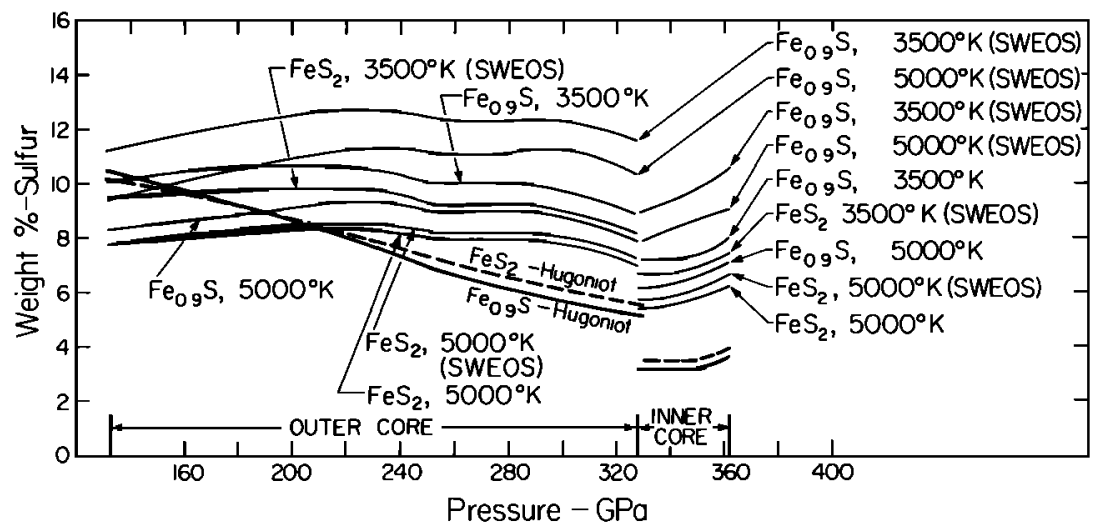

Fig. 10. Sulfur content (in weight percent) versus pressure in the inner and outer cores as inferred from constraining shock wave data to seismologically determined [Hart, 1977; Hart et al., 1977] pressure-density distributions for the earth. SWEOS indicates shock wave equation of state. Unlabeled curves are calculated using the fourth-order finite strain equation. 
the sun is 2.00 with a maximum value of 3.39 and minimum value of 1.17 , whereas this ratio is 1.78 in $\mathrm{CCl}$ carbonaceous chondrites. Using lower bounds of 9 and $6.5 \mathrm{wt} \% \mathrm{~S}$ in the outer and inner core implies $5.2 \times 10^{24} \mathrm{~mol}$ of $S$ in the core, whereas using 12 and $8.5 \mathrm{wt} \% \mathrm{~S}$ in the outer and inner core implies $7.2 \times 10^{24} \mathrm{~mol}$ of $\mathrm{S}$ in the total core. The above values assume that no appreciable $S$ is contained in the mantle. For pure pyroxene and olivine mantles, the assumed value of the $\mathrm{Fe} /(\mathrm{Fe}+\mathrm{Mg})$ ratio of 0.12 [Ringwood, 1975] implies maximum and minimum $\mathrm{Si} / \mathrm{S}$ ratios for the earth of 7.4 and 3.5, respectively. These values imply depletion in $S$ of the earth relative to carbonaceous chondrites of 1.75 to 3.2 . A similar calculation for the $\mathrm{Fe} / \mathrm{S}$ ratio for a pure pyroxene and olivine mantle, again with $\mathrm{Fe} /(\mathrm{Fe}+\mathrm{Mg})=0.12$, gives $\mathrm{Fe} / \mathrm{S}$ values varying from 5.1 to 13.5 . In relation to $\mathrm{CCl}$ chondrites, the earth is again slightly depleted in S by a factor of 2.8 to 7.5 .

Ringwood [1977] has discussed the depletions of lithophile elements such as $\mathrm{Na}, \mathrm{K}$, and $\mathrm{Rb}$ in the mantle and the apparent depletion of $S$ in the crust and mantle in relation to $\mathrm{CCl}$ carbonaceous chondrites. As the above mentioned lithophile elements are less volatile than $S$ under conditions of relatively high partial pressures of $\mathrm{H}_{2}$, such as are believed to have been present during the time of formation of the earth, their mantle depletions are hard to explain. A possible, and at present, highly speculative hypothesis to explain the depletion of $\mathbf{K}$ exists wherein it is suggested that $K$ undergoes an electronic transition, such that $3 d$ rather than $4 s$ orbitals dominate chemical bonding, giving the element a siderophile chemical affinity and hence making it possible to dissolve in liquid iron or sulfide melts at very high pressures [Goettel, 1972; Bukowinski and Knopoff, 1976; Murthy, 1976]. However, Ringwood [1977] has pointed out that some elements with $3 d$ orbitals are not siderophyllic. Also, Oversby and Ringwood [1972, 1973] and Ganguly and Kennedy [1977] found no experimental evidence for this hypothetical transformation in potassium silicates or sulfides up to $\sim 4 \mathrm{GPa}$. Moreover, Ringwood [1977] has pointed out that to have depletions of the other depleted elements which are ordinarily more refractory than $S$, such as $\mathrm{Na}$ and $\mathrm{Rb}$, upon accretion of the earth requires that the earth accumulated within a chemical environment which was $>900^{\circ} \mathrm{C}$ and depleted in hydrogen by a factor of $100-200$, in relation to $\mathrm{S}$ in the solar nebula. A similar reduction in the $\mathrm{H}_{2}$ abundance upon earth accretion must also be involved if, as Ringwood [1977] proposed, $\mathrm{FeO}$ is a significant component of the core. The premise in Ringwood's argument against a sulfur-bearing core is that the earth accumulated the full chondritic, or solar, abundance of S. As demonstrated above, the shock wave data are consistent with the earth's having sulfur as the major iron-alloying element in the core and also having the earth depleted in $\mathrm{S}$ by factors of 1.8-3.2 with respect to $\mathrm{Si}$ abundances or 2.8-7.5 with respect to Fe abundances in carbonaceous chondrites.

Acknowledgments. I am indebted to Harold A. Richeson for so carefully managing our gun facility; David A. King, with whom I initially began this study; Ian Jackson, whose help was critical in firing the last of these experiments; and the support of the National Science Foundation (grant EAR77-23156). I appreciate the very helpful critical comments of Raymond Jeanloz, Don L. Anderson, John Verhoogen, Robin Brett, William A. Bassett, and Ian Jackson on the final manuscript. Contribution 3003, Division of Geological and Planetary Sciences, California Institute of Technology, Pasadena, California 91125 .

\section{REFERENCES}

Ahrens, T. J., C. F. Petersen, and J. T. Rosenberg, Shock compression of feldspars, J. Geophys. Res, 74, 2727-2746, 1969.
Ahrens, T. J., J. H. Lower, and P. L. Lagus, Equation of state of forsterite, J. Geophys. Res., 76, 518-528, 1971.

Ahrens, T. J., J. D. O'Keefe, and R. V. Gibbons, Shock compression of a recrystallized anorthositic rock from Apollo 15, Proc. Lunar Sci. Conf. 4th. 2575-2590, 1973.

Alder, B. J., and M. Trigueros, Suggestion of a eutectic region between the liquid and solid core of the earth, J. Geophys. Res., 82, 25352539, 1977.

Al'tshuler, L. V., K. K. Krupnikov, and M. I. Brazhnik, Dynamic compressibility of metals under pressures from 400,000 to $4,000,000$ atmospheres, Sov. Phys. JETP, 34, 614, 1958 a.

Al'tshuler, L. V., K. K. Krupnikov, B. N. Ledenev, V. I. Zhuchikhin, and M. I. Brazhnik, Dynamic compressibility and equation of state of iron at high pressures, Zh. Eksp. Teor. Fiz., 34, 4, 1958 .

Al'tshuler, L. V., A. A. Bakanova, and R. F. Trunin, Shock adiabats and zero isotherms of seven metals at high pressures, Sov. Phys. JETP, 15, 65-74, 1962.

Anderson, D. L., A seismic equation of state, Geophys. J. Roy Astron. Soc., 13, 9-30, 1967.

Anderson, D. L., Internal constitution of Mars, J. Geophys. Res., 77. 789-795, 1972.

Anderson, D. L., and O. L. Anderson, The bulk modulus-volume relationship for oxides, J. Geophys. Res., 75, 3494-3500, 1970.

Berman, H., A torsion microbalance for the determination of specific gravities of minerals, Amer. Mineral., 24, 435-440, 1939.

Birch, F., Elasticity and constitution of the earth's interior, $J$. Geophys. Res., 57, 227, 1952.

Birch, F., Density and composition of mantle and core, J. Geophys. Res., 69, 4377, 1964.

Birch, F., Compressibility; elastic constants, Handbook of Physical Constants, Geol. Soc. Amer. Mem. 97, 93-173, 1966.

Brett, R., The current status of speculations on the composition of the core of the earth, Rev. Geophys. Space Phys., 14, 375-383, 1976.

Brett, R., and P. M. Bell, Melting relations in the Fe-rich portion of the Fe-FeS system at $30 \mathrm{~kb}$ pressure, Earth Planet. Sci. Lett., 6, 479482, 1969.

Bridgman, P. W., Linear compressions to $30,000 \mathrm{~kg} / \mathrm{cm}^{2}$ including relatively incompressible substances, in Proc. Amer. Acad. Arts Sci., 77, 187-234, 1949.

Bukowinski, M. T. S., and L. Knopoff, Electronic structure of iron and models of the earth's core, Geophys. Res. Lett., 3, 45-48, 1976.

Buolos, M. S., and O. K. Manual, The xenon record of extinct radioactivities in the Earth, Science, 174, 1334-1336, 1971.

Clendenen, R. L., and H. G. Drickamer, Lattice parameters of nine oxides and sulfides as a function of pressure, J. Chem. Phys., 44, 4223-4228, 1966.

Corbett, M., Selected Powder Diffraction Data for Minerals, 1st ed., p. 511, American Society for Testing and Materials, Philadelphia, Penn., 1974.

Davies, G. F., Quasi-harmonic finite strain equations of state of solids, J. Phys. Chem. Solids, 34, 1417-1429, 1973.

Doran, D. G., Measurement of shock pressures in solids, in High Pressure Measurement, edited by A. A. Giardini and E. C. Lloyd, pp. 59-86, Butterworths, London, 1963.

Duvall, G. E., and R. A. Graham, Phase transitions under shock-wave loading, Rev. Mod. Phys., 49, 523-579, 1977.

Fanale, F. P., and W. A. Cannon, Physical absorption of rare gas on terrigenous sediments, Earth Planet. Sci. Lett., II, 362-368, 1971.

Ganguly, J., and G. C. Kennedy, Solubility of K in Fe-S liquid, silicate-K-(Fe-S) liquid equilibria, and their planetary implications, Earth Planet. Sci. Lett., 35, 411-420, 1977.

Gilbert, F., and A. M. Dziewonski, An application of normal mode theory to the retrieval of structural parameters and source mechanisms from seismic spectra, Phil. Trans. Roy. Soc. London, 278, 187$269,1975$.

Gilbert, F., A. Dziewonski, and J. Brune, An informative solution to a seismological inverse problem, in Proc. Nat. Acad. Sci. U.S., 70, 1410-1413, 1973.

Goettel, K. A., Partitioning of potassium between silicates and sulphide melts: Experiments relevant to the earth's core, Phys. Earth Planet. Interiors, 6, 161, 1972.

Goldschmidt, V. M., Der Stöffwechsel der Erde, Videnskaps, Skifler Kristiania, Math. Naturw. BI., II, 1922.

Grossman, L., Condensation in the primitive solar nebulae, Geochim. Cosmochim. Acta. 36, 597-619, 1972.

Grover, R., Liquid metal equation of state based on scaling, J. Chem. Phys., 33, 3435-3441, 1971.

Hall, H. T., and V.R. Murthy, The early chemical history of the earth: Some critical elemental fractionations, Earth Planet. Sci. Lett., II, 239-244, 1971. 
Hart, R. S., The distribution of seismic velocities and attenuation in the earth, Ph.D. thesis, 354 pp., Calif. Inst. of Technol., Pasadena, 1977.

Hart, R. S., D. L. Anderson, and H. Kanamori, The effect of attenuation on gross earth models, J. Geophys. Res., 82, 1647-1654, 1977.

Irvine, R. D., and F. D. Stacey, Pressure dependence of the thermal Grüneisen parameter, with application to the earth's lower mantle and outer core, Phys. Earth Planet. Interiors, I1, 157-165, 1975.

Jacobs, J. A., The Earth's Core, 253 pp., Academic, New York, 1975.

Jamieson, J. C., H. H. Demerest, Jr., and D. Schiferl, A reevaluation of the Grüneisen parameter for the earth's core, J. Geophys. Res., $83,5929,1978$.

Jeanloz, R., and T. J. Ahrens, Pyroxenes and olivines: Structural implications of shock-wave data for high pressure phases, in HighPressure Research: Applications to Geophysics, edited by M. H. Manghnani and S. Akimoto, pp. 439-461, Academic, New York, 1977.

Johnston, D. H., and M. N. Toksöz, Internal structure and properties of Mars, Icarus, 32, 73-84, 1977.

Jones, A. H., W. M. Isbell, F. H. Shipman, R. D. Perkins, S. J. Green, and C. J. Maiden, Material properties measurements for selected materials, Interim Rep. NAS2-3427, 55 pp., Gen. Motors Mater. and Struct. Lab., Warren, Mich., 1968.

Kennedy, G. C., and G. H. Higgins, Temperature gradients at the core-mantle interface, Moon, 7, 14-21, 1973.

King, D. J., and T. J. Ahrens, Shock compression of iron sulphide and the possible sulfur content of the earth's core, Nature Phys. Sci., 243, 82-84, 1973.

Knopoff, L., and G. J. F. MacDonald, An equation of state for the core of the earth, Geophys. J. Roy. Astron. Soc., 3, 68-77, 1960.

Lewis, J. S., Consequences of the presence of sulfur in the core of the Earth, Earth Planet. Sci. Lett., II, 130-134, 1971.

Lewis, J. S., Metal/silicate fractionation in the solar system, Earth Planet. Sci. Lett., 15, 286-290, 1972.

Lyzenga, G., and T. J. Ahrens, The relation between the shockinduced free-surface velocity and post-shock density of solids, $J$. Appl. Phys., 49, 201-204, 1978.

Mason, G., Composition of the earth, Nature, 2II, 616, 1966.

McQueen, R. G., and S. P. Marsh, Shock wave compression of ironnickel alloys and the earth's core, J. Geophys. Res., 7I, 1751, 1966.

McQueen, R. G., S. P. Marsh, and J. N. Fritz, Hugoniot equation of state of twelve rocks, J. Geophys. Res., 72, 4999-5036, 1967.

McQueen, R. G., S. P. Marsh, T. W. Taylor, J. N. Fritz, and W. J. Carter, The equation of state of solids from shock wave studies, in High Velocity Impact Phenomena, edited by R. Kinslow, pp. 294419, Academic, New York, 1970.

Mulargia, F., Is the common definition of the Mie-Grüneisen equation of state inconsistent?, Geophys. Res. Lett., 4, 590-592, 1977.

Murthy, V. R., Composition of the core and the early chemical history of the earth, in The Early History of the Earth, edited by B. F. Windley, pp. 21-31, John Wiley, New York, 1976.

Murthy, V. R., and H. T. Hall, The chemical composition of the earth's core: Possibility of sulphur in the core, Phys. Earth Planet. Interiors, 2, 276, 1970.

Murthy, V. R., and H. T. Hall, The origin and composition of the Earth's core, Phys. Earth Planet. Interiors, 6, 123-130, 1972.

Okal, E. A., and D. L. Anderson, Theoretical models for Mars and their seismic properties, Icarus, 33, 514-528, 1978.

Oversby, V. M., and A. E. Ringwood, Potassium distribution between metal and silicate and its bearing on the occurrence of potassium in the earth's core, Earth Planet. Sci. Lett., 14, 345-347, 1972.

Oversby, V. M., and A. E. Ringwood, Reply to comments by K. A. Goettel and J. S. Lewis, Earth Planet. Sci. Lett., 18, 151, 1973.
Pichulo, R. O., T. Takahashi, and J. S. Weaver, High pressure polymorphism of FeS (abstract), Eos Trans. AGU. 57, 340, 1976.

Ringwood, A. E., The chemical composition and origin of the earth, Advan. Earth Sci. Contrib. Int. Conf. MIT, 287-356, 1966.

Ringwood, A. E., Composition and Petrology of the Earth's Mantle, 618 pp., McGraw-Hill, New York, 1975.

Ringwood, A. E., Composition of the core and implications for origin of the earth, Geochem. J., II. 111-136, 1977.

Ringwood, A. E., and S. E. Keeson, Composition and origin of the moon, Proc. Lunar Sci. Conf. 8th, 1977.

Robie, R. A., P. M. Bethke, M. S. Toulmin, and J. L. Edwards, X-ray crystallographic data, densities, and molar volumes of minerals, Handbook of Physical Constants, Geol. Soc. Amer. Mem., 97, 2773, 1966.

Rodean, H. C., Thermodynamic relations for shock waves in materials with a linear relation between shock-wave and particle velocities, $J$. Appl. Phys., 48, 2384-2395, 1977.

Ross, T. E., and L. H. Aller, The chemical composition of the sun, Science, 19I, 1223-1229, 1976.

Ruof, A. L., Linear shock-velocity-particle-velocity relationship, $J$. Appl. Phys., 38, 4976-4980, 1967.

Ryzhenko, B., and G. C. Kennedy, The effect of pressure on the eutectic in the system Fe-FeS, Amer. J. Sci., 273, 803-810, 1973.

Scott, S. D., Experimental calibration of the sphalerite geobarometer, Econ. Geol., 68, 466-474, 1973.

Shaw, G. H., Effects of core formation, Phys. Earth Planet. Interiors, 16. 361-369, 1978.

Simakov, G. V., M. N. Pavlovskiy, N. G. Kalashnikov, and R. F. Trunin, Shock compressibility of twelve minerals, Izv. Acad. Sci. USSR Phys. Solid Earth, 8, 11-17, 1974.

Simmons, G., and F. Birch, Elastic constants of pyrite, J. Appl. Phys., 34, 2736-2738, 1963.

Simmons, G., and H. Wang, Single Crystal Elastic Constants and Calculated Aggregate Properties: A Handbook, 2nd ed., 370 pp., MIT Press, Cambridge, Mass., 1971.

Smith, J. V., Possible controls on the bulk composition of the Earth: Implications for the origin of the Earth and Moon, Proc. Lunar Sci. Conf. 8th, 333-370, 1977.

Stacey, F. D., Physics of the Earth, 2nd ed., 414 pp., John Wiley, New York, 1977.

Taylor, L. A., and H. K. Mao, A high pressure polymorph of troilite, FeS, Science, I70, 850-851, 1970.

Usselman, T. M., Experimental approach to the state of the core, 1, The liquidus relations of the Fe-rich portion of the Fe-Ni-S system from 30-100 kb, Amer. J. Sci., 257, 278-290, 1975a.

Usselman, T. M., Experimental approach to the state of the core, 2, Composition and thermal regime, Amer. J. Sci., 257, 291-303, $1975 b$.

Vashchenko, V. Y., and V. N. Zubarev, Concerning the Grüneisen constant, Sov. Phys. Solid State, 5, 653, 1963.

Wackerle, J., Shock-wave compression of quartz, J. Appl. Phys., 33, 922-937, 1962.

Walsh, J. M., and R. H. Christian, Equation of state of metals from shockwave measurements, Phys. Rev., 97, 1544-1556, 1955.

Wang, C. Y., Temperature in the lower mantle, Geophys. J. Roy. Astron. Soc., 27, 29-36, 1972.

(Received January 9, 1978;

revised July 12, 1978;

accepted October 12,1978.) 